\title{
DESIGN OF \\ FREE-AIR IONIZATION CHAMBERS
}

Handbook 64

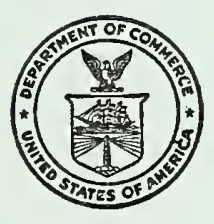

United States Department of Commerce National Bureau of Standards 


\section{The National Bureau of Standards}

\section{Functions and Activities}

The functions of the National Bureau of Standards are set forth in the Act of Congress, March 3, 1901, as amended by Congress in Public Law 619, 1950. These include the development and maintenance of the national standards of measurement and the provision of means and methods for making measurements consistent with these standards; the determination of physical constants and properties of materials; the development of methods and instruments for testing materials, devices, and structures; advisory services to Government Agencies on scientific and technical problems; invention and development of devices to serve special needs of the Government; and the development of standard practices, codes, and specifications. The work includes basic and applied research, development, engineering, instrumentation, testing, evaluation, calibration services, and various consultation and information services. A major portion of the Bureau's work is performed for other Government Agencies, particularly the Department of Defense and the Atomic Energy Commission. The scope of activities is suggested by the listing of divisions and sections on the inside of the back cover.

\section{Publications}

The results of the Bureau's work take the form of either actual equipment and devices or published papers; these papers appear either in the Bureau's own series of publications or in the journals of professional and scientific societies. The Bureau itself publishes three monthly periodicals, available from the Government Printing Office: The Journal of Research, which presents complete papers reporting technical investigations; the Technical News Bulletin, which presents summary and preliminary reports on work in progress; and Basic Radio Propagation Predictions, which provides data for determining the best frequencies to use for radio communications throughout the world. There are also five series of nonperiodical publications: The Applied Mathematics Series, Circulars, Handbooks, Building Materials and Structures Reports, and Miscellaneous Publications.

Information on the Bureau's publications can be found in NBS Circular 460, Publications of the National Bureau of Standards (\$1.25) and its Supplement (\$0.75), available from the Superintendent of Documents, Government Printing Office, Washington 25, D. C. 
UNITED STATES DEPARTMENT OF COMMERGE • Sinclair Weeks, Secretary NATIONAL BUREAU OF STANDARDS - A. V. Astin, Director

\section{Design of \\ Free-Air Ionization Chambers}

H. O. Wyckoff and F. H. Attix

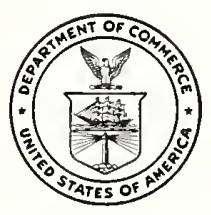

National Bureau of Standards Handbook 64 Issued December 13, 1957 



\section{Preface}

In the past, free-air standard chambers have been used in a few of the national standards laboratories. This was sufficient for the need at that time, for these chambers are principally used for the calibration of the smaller clinical and field instruments. With the increase in radiation therapy, more and more of the national laboratories have had to become interested in the problem. Also many industries have found it worthwhile to provide such calibration facilities.

In the past several years, some of the larger national standards laboratories have intercompared their free-air chambers. Differences between the chambers after proper corrections are applied amount to the order of 0.5 percent. In order to disseminate the information obtained during these calibrations and during the evaluations of the corrections which are to be applied to their readings, it seemed worth while to incorporate it in to a single publication. The present report depends largely upon information obtained at the National Bureau of Standards, but includes also such information from published work of other laboratories as is pertinent to the problem.

This is a problem that is of interest to both the National Committee on Radiation Protection and Measurements, and the International Commission on Radiological Units and Measurements. The authors would like to express their gratitude to members of these two groups who have read the manuscript and have given them the benefit of their criticisms. In this regard, the authors wish especially to thank C. Garrett of the National Research Council, Ottawa, Canada, who suggested several additional topies to be included in the report.

\section{A. V. Astin, Director.}




\section{Contents}

Preface

Page

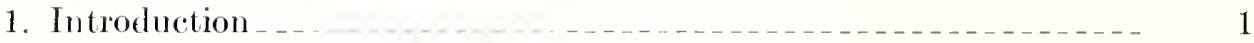

1.1. Characteristics of free-air chambers _............... 1

2. Details of chamber design 3

2.1. The defined mass of air

2.2. Diaphragm ..... 3

2.3. Field distortion $\ldots \ldots \ldots \ldots \ldots$

a. Distortion near guard wires or strips____._. 6

b. Misalinement of the collector plate and adjacent guard plates 6

c. Contact potential difference between guard plates and collector electrodes

d. Externally imposed potential differenee between collector and guard electrodes.

2.4. X-ray scattering and electron losses $\ldots \ldots \ldots \ldots$

2.5. Aperture-to-collector distance $\ldots$

2.6. Losses from ion recombination ...

2.7. Air attenuation corrections

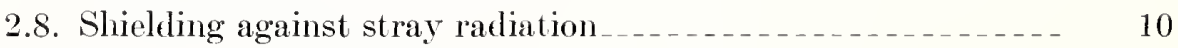

3. Current or charge measurement 10

4. Examples.

5. Accuracy of free-air chamber measurements

6. References .

IV 


\title{
Design of Free-Air Ionization Chambers
}

\author{
H. O. Wyckoff and F. H. Attix
}

\begin{abstract}
General design characteristies are given for standard free-air type ionization chambers for X-rays from 50 to 500 kilovolts. Included are the plate-separation requirements, elimination of electric-field distortion, data on air-attenuation and scattering effects, current measurement techniques, and other relevant features.
\end{abstract}

\section{Introduction}

The roentgen has been used for many years as a umit of X-ray dose. The free-air ionization chamber is the instrument employed in the experimental realization of this unit. "Until recently, free-air-chamber installations have been confined principally to some of the national standards laboratolies. However, a number of other laboratories have become interested in setting up their own primary standards for measurement in roentgens. In addition, there have been several papers [1 to 7$]^{*}$ pointing up small errors in the existing instruments.

Generally, such primary standards are used only for calibration of secondary instruments which have greater flexibility for field use. For some applications, such secondary instruments should have an accuracy of perhaps \pm 1 pereent. Thus, it is desirable that calibration of such secondary standard instruments be reproducible to within 1 percent when measured by the various primary standard instruments of the world. As the calibration of secondary instruments in terms of the primary is not itself without some experimental elror, it is necessary to know the over-all errors of the primary instrument to, say, \pm 0.5 percent. Thus all of the factors influencing this accuracy must be known to a few tenths of 1 percent. A review of the design criteria and of their absolute accuracies therefore seems desirable.

The International Commission on Radiological Units and Measurements has defined [8] the unit of X-ray dose as follows: "One roentgen is an exposure dose of $\mathrm{X}$ - or gamma radiation such that the associated corpuscular emission per 0.001293 gram of air produces, in air, ions carrying 1 electrostatic unit of quantity of electricity of either sign." According to this definition, a measurement of the number of roentgens requires that one measure all of the ionization produced in air by the high-speed electrons that are themselves produced within the defined mass of air. Real difficulties arise in the measurement of the ionization as required by the definition, so the principle of electronic equilibrium is always used in practice.

According to the principle of electronic equilibrium, within a medium under uniform irradiation the ionization produced outside of a specified mass, $m$, by high-speed electrons generated inside $m$ is compensated by ionization in $m$ produced by highspeed electrons generated outside of $m$ [9]. Elec-

* Figures in brackets indicate the literature references at the end of this Handbook. trons produced out to a distance from $m$ equal to the electron range thus contribute to the ionization in $m$. In order to conform to the definition of the roentgen, it is obvious that the ionization produced by the scattered radiation from this region must be eliminated in the measurement.

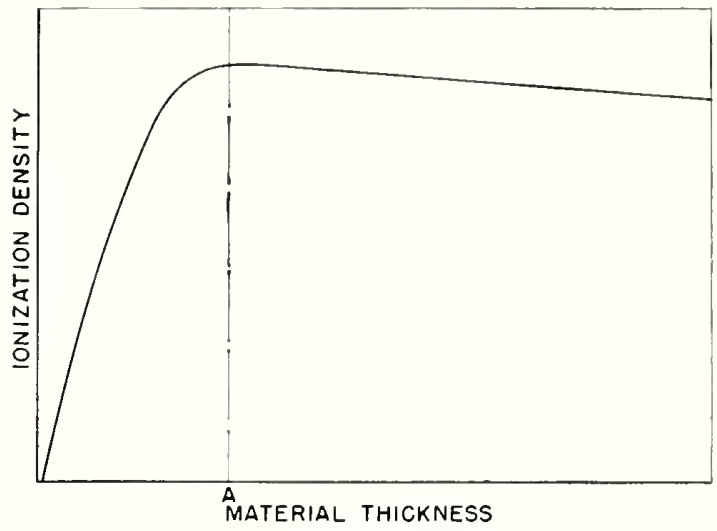

Frgure 1. Growth of ionization density in a small volume of gas from an initially electron-free beam of photon radiation as the gas is surrounded by more and more material.

Electronic equilibrium is said to exist for a thickness, $A$, of material.

Figure 1 assists in picturing this electronic equilibrium. This figure indicates the ionization density in a small volume of gas due to an initially electron-free beam of $\mathrm{X}$ - or gamma radiation as the gas is smrounded by more and more material. The photon beam interacts with the material to produce high-speed electrons, but in the process is itself reduced in intensity. These two competing mechanisms cause an initial increase in the curve (due principally to the increase in the number of high-speed electrons), a plateau, and finally a tecrease (principally due to the decreased intensity of the photon beam). A thickness of material corresponding to $\mathrm{A}$ in figure 1 is approximately equal to the electron range in the material.

Special considerations involved in applying the idea of electronic equilibrium to free-air chambers will be brought out in the next section.

\subsection{Characteristics of Free-Air Chambers}

While free-air chambers of different detailed construction have been made, they all have the general characteristics indicated in figure 2. This is a plan view of a parallel-plate ionization chamber 
like the ones used at the National Bureau of Standards and at the National Physical Laboratory in Great Britain. Chambers having other electrode configurations are also used as standards in other laboratories. ${ }^{1}$ The plate system is contained in a radiation-shielded box. A known area of the horizontal X-ray beam is defined by the diaphragm, D, so that a beam of photons passes centrally between the plates. A high potential (field strength of the order of $100 \mathrm{v} / \mathrm{cm}$ ) on plate $\mathrm{H}$, with respect to the other plates, sweeps out the ionization produced in the air between the plates. The ionization is measured for a length, L, determined by the limiting lines of force to the edges of the collector, C. 'These lines are made straight and perpendicular to the collector by the guard plates, G, and surrounding guard wires or strips, W. The latter are comnected to a resistancedividing network to grade the potential uniformly across the gap between $\mathrm{C}$ or $\mathrm{G}$, and H. Generally, guard plates like $\mathrm{G}$ are not considered necessary above and bolow the collector because there the ionization density is low.

Ionization is collected throughout the region enclosed by the dashed lines, F. Some electrons, such as $e_{1}$, having paths predominantly perpendicular to the $\mathrm{X}$-ray beam, will expend their entire energies within the ion-collecting region, assuming the plate separation to be sufficiently large. (Actually, of course, the electron paths are not straight as indicated.) Others, like $e_{2}$, will pass out of that region and produce ionization where it will be collected on one of the guard plates and hence will not be measured. Under the electronic equilibrium condition, this ionization loss is just compensated by the contribution of other clectrons such as $e_{3}$, assuming air attenuation of the primary beam to be small. Such a condition can exist only if the two ends of the box housing the chamber are at a distance (from the ion-collecting region) greater than the range of the electrons present, or about half the distance required for plate separation.

Electrons, like $e_{4}$, resulting from scattered photons, produce ionization which is not included in the definition of the roentgen, as these electrons do not originate directly from photons collimated by D. Their ionization contribution is usually assumed to be negligible. In large chambers, however, that assumption may not be justified. On the other hand, the presence of such unwanted ionization tends to compensate for ionization losses due to insufficient plate separation.

In the calibration of a secondary radiation instrument by a standard chamber, a substitution method is used. The dose rate is determined from the measurements of the ionization in the standard chamber, this chamber is remored, and the secondary instrument is placed at the position formerly occupied by the aperture of the standard

1 The advantages of the various kinds of configurations are discussed by Rajewsky, et al. [32].

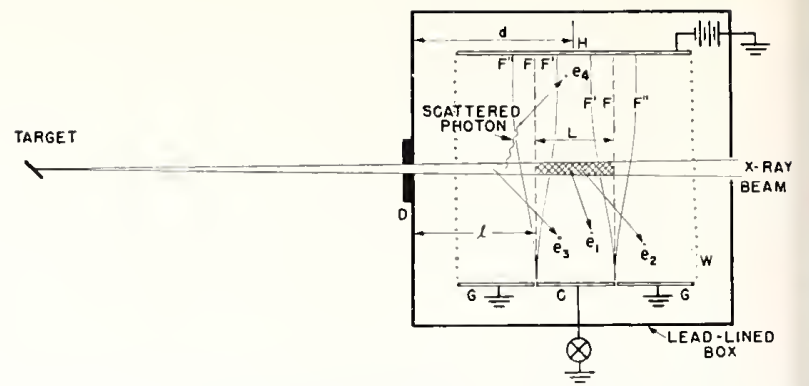

Figure 2. Schematic plan view of a parallel-plate free-air chamber.

chamber. Therefore it is necessary to compute the dose rate at the aperture of the standard chamber. This computation requires a knowledge of the absorption of $\mathrm{X}$-rays in the air between the aperture and the weighted positions of electron production. Thus, for the X-ravs producing electrons such as $e_{3}$ (fig. 2), the absorption is less than for those producing electrons like $e_{1}$. However, it has becn shown [5] that even for 500-kv X-rays the contribution of electrons like $e_{3}$ is so small that the effective center for electron production is essentially the center of the collector. Therefore the air-absorption correction should be made for the distance between the center of the collector and the aperture.

In the Swedish type of free-air chamber [10], the high-roltage plate is a eylinder, and the second electrode is also cylindrical and coaxial with it. A central portion of this inner electrode serves as collector. The diaphragmed beam passes through the chamber parallel to its axis and between the center and outer electrodes. The Kustner-type chanrber [11] also uses an outer cylindrical highvoltage electrode. However, the beam passes along the axis of the chamber and the collector is placed between this radiation beam and the outer electrode.

The factors that must be investigated for the proper design of one of these chambers include (1) the diaphragm system, (2) the effective length of the region of ion collection as it is distorted by variations in the electric field, (3) the spacing between the beam and the high-roltage electrode, and between the beam and the collector electrode, (4) the distance between the diaphragm and the collector, (5) the collecting potential required in order to achieve saturation (i. e., so that negligible recombination of the ionization is permitted), (6) the air absorption between the center of the collector and the aperture, and (7) radiation shielding of the box.

In the present report information is collected on the above design factors for X-rays of 60 to $500 \mathrm{kv}$. As an example of the use of these data, an estimate is made of the corrections to be applied to the measurements by two free-air chambers. This is compared with the data obtained in an experimental intercom arison between the chambers. 


\section{Details of Chamber Design}

\subsection{The Defined Mass of Air}

In a free-air chamber the aperture area and the length of the collecting electrode (along the beam direction) define a volume of air. The definition of the roentgen, on the other hand, requires measurement of the ionization per mass of $0.001293 \mathrm{~g}$ of (dry) air (which numerically equals the density of dry air, in grams per cubic centimeter, at $0^{\circ} \mathrm{C}$ and $760 \mathrm{~mm}$ of mercury). Thus one must apply suitable corrections to the ionization measured under other conditions than these, to reduce the results to the standard conditions. For ordinary operating temperatures and pressures, the perfect-gas law may be used. If a unit mass of air is defined as $0.001293 \mathrm{~g}$, the number of unit masses of air in a given volume $V$ $\left(\mathrm{cm}^{3}\right)$ equals

$$
\frac{273.2}{T} \frac{P V}{760}
$$

where $T$ (in degrees Kelvin) is the air temperature, ${ }^{2}$ and $P$ (in millimeters of mercury) is the pressure. However, air usually contains water vapor. As the electron densities of air and water vapor are different, the density must be corrected for this difference if absolute determinations to better than the order of 1 percent are desired. Furthermore, the energy $W^{\prime}$, needed to produce an ion pair in water vapor, is somewhat less than that in air. ${ }^{3}$ For humid air, the effective number of unit masses of air [12] within volume $V$ equals ${ }^{4}$

$$
\frac{273.2}{T} \frac{\left(P-0.238 P_{1}\right) V}{760}
$$

where $P_{1}$ is the vapor pressure of the moisture in the air (in $m m$ of mercury). The volume, $V$, is determined for a free-air chamber by the product of the area of the diaphragm aperture and the effective length of the collecting region [13] (see section 2.3.).

\subsection{Diaphragm}

Usually the diaphragm consists of a disk of dense metal attached to the front of the box in such a way that no X-rays can leak past its outer edge.

${ }^{2}$ Because the air in the chamber may be heated slightly by the resistors used for collector-field uniformity and because drafts may cause temperature gradients, the air temperature should be measured inside the box itself.

${ }_{3}$ According to a private communication from $\mathrm{G}$. Failla, $\mathrm{II}_{\mathrm{H}_{2} \mathrm{O}} \cong 0.9 \mathrm{II}_{\mathrm{air}}$

This value has been assumed here in weighting the effectiveness of the watervapor electrons.

+ In addition, for low-energy photons, water vapor is less effective in producing ionization than are those of air becanse the energy absorption coefficient for air is greater. Thus, for example, at $50 \mathrm{kev}$, the energy absorption coefflcient for air is about \& percent greater (per electron) than that for $\mathrm{H}_{2} \mathrm{O}$ vapor. At room temperatures with 100 percent humidity, the water vapor electrons constitute $\approx 2$ percent of the electrons present. Therefore the electrons constitute $\approx 2$ percent of the elo energy absorbed (and thus the ionization) is about 0.2 percent less than if the same number of electrons of dry air were present. At kev's down tr $10 \mathrm{k} \rho \mathrm{v}$, this remains in the neighborhood of 0.2 percent (see table 1 in ref [8]). At $80 \mathrm{kev}$, it has dropped to $\approx 0.1$ percent, and at $100 \mathrm{kev}$ is nearly zero. Note that this is separate from the effect of electron density which we have taken into account already. However, the relative humidity is usually 50 percent or less in order to secure low insulator leakage. Therefore this effect will not be important in most cases.
The hole in the middle of this disk, through which the X-rays pass into the box, is usually cylindrical in shape because of the ease of construction and measurement (although the Kustnertype chamber sometimes uses a crescent-shaped aperture). The size of this hole is arbitrary, although certain factors shoukd be considered in making a choice.

Too small a hole may result in:

a. Difficulty in machining.

b. Difficulty in accurately measuring the area.

c. Criticality of alinement with the $\mathrm{X}$-ray beam.

d. Excessive secondary radiation from the surface. ${ }^{5}$

Too large a hole may cause:

a. Excessive ion recombination at a given collecting potential.

b. Attenuation of the X-rays in the guard wires or strips on the front of the plate system. (Removal of the wires or strips increases field distortion.)

c. Increased ionization losses due to inadequate plate separation.

d. Nonuniformity of the X-ray beam over the area of the hole.

$A$ hole of the order of $1 \mathrm{~cm}$ in diameter has been found to be adequate for the encrgy region under consideration. Ioles of this diameter have becn produced in tungsten alloy, by reasonably careful shop practices, to be circular and of uniform diameter within $1 \mu$, over a length of $1 \mathrm{~cm}$.

The thickness of the peripheral region of the diaphragm disk should produce an X-ray attenuation as great as that of the shielding on the front of the box (which is discusser later). The attenuation near the edge of the hole need not be so great, however, because the thickness necessary to attain this attenuation would cause the alinement of the diaphragm aperture with the X-ray beam to become unnecessarily critical. It is preferable to taper a portion of the aperture (on the side away from the $\mathrm{X}$-ray souree) in the manner indicated in fioure 3. While the angle of taper, $\theta$, is not critical, it should be chosen small enough to

5 König [15] has shown that the fractional contribution of secondary rarliation from the cylindrical surface of the aperture is inversely proportional to the aperture diameter.

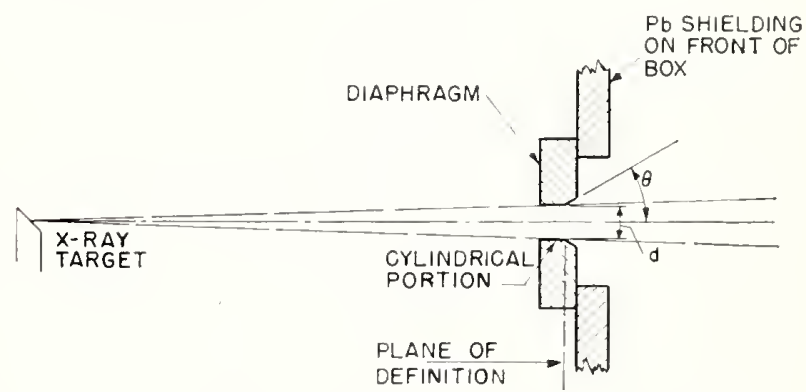

FIGURE 3. Defining diaphragm with an aperture diameter, $d$, and taper, $\theta$, 
preserve the full attenuation over most of the diaphragm area and to make negligible the penetration of $\mathrm{X}$-rays through the edges of the aperture at the plane of definition (i. e., the plane where the aperture limits the solid angle of X-rays passing through). $\theta$ must be large enough, however, so that the plane of definition does not shift to the rear surface of the diaphragm for the smallest target-to-diaphragm distance to be employed. The experience at the Bureau has shown that $\theta=45^{\circ}$ is adequate for the energy range under consideration.

Selection of the depth of the cylindrical part of the aperture, of course, depends on the material used in constructing the diaphragm. Gold, lead, and tungsten alloy $(\sim 89 \% \mathrm{~W}, 7 \% \mathrm{Ni}, 4 \% \mathrm{Cu})$ have all been used at the Bureau. Aperture areas in diaphragms of gold and lead have been found stable to within 0.1 percent over a period of 25 vears. However, these materials are not readily machinable with high precision. Tungsten alloy machines very well and is therefore probably preferable. Although the authors' experience with this material cover's only a 3-year period, it has been found to maintain very closely its dimensions.

Temperature coefficients of linear expansion he between 5 and $20 \times 10^{-6} /{ }^{\circ} \mathrm{C}$ for these three materials; thus the alteration of aperture dimensions by changing temperature is negligible for temperature ranges usually encountered.

Table 1 gives the narrow-beam attenuation coefficients for the above tungsten alloy, for monochromatic irradiation. Diaphragms should be designed to reduce the X-ray penetration (integrated over the diaphragm surface) to a negligible fraction (less than 0.1 percent) of the X-rays entering the box through the aperture.

TABLE 1. Monochromatic attenuation coefficients for narrow-beam conditions in tungsten alloy $(\sim 89 \% \mathrm{~W}+7 \%$ $\mathrm{Ni}+4 \% \mathrm{Cu}$

\begin{tabular}{|c|c|}
\hline kev & $\mu\left(\mathrm{cm}^{-1}\right)$ \\
\cline { 1 - 2 } 50 & 71.2 \\
100 & 66.8 \\
150 & 23.1 \\
200 & 11.6 \\
300 & 4.90 \\
400 & 2.96 \\
500 & 2.14 \\
&
\end{tabular}

A second diaphragm located some distance behind the defining diaphragm (in the direction away from the $\mathrm{X}$-ray source) has sometimes been used. This is intended to stop X-rays scattered from the first diaphragm. Neasurements at the Bureau have shown that this extra diaphragm is (a) unnecessary because the diaphragm scatter and fluorescence amounts to only a few hundred ths of 1 percent of the radiation passing through the aperture ${ }^{6}$ and (b) undesirable because the presence of a scatter diaphragm increases the criticality of the beam alinement.

${ }^{6}$ König [15] indicates that the seatter from a 1 -cm-diameter aperture is about 0.3 percent of that passing through the aperture. However, much smaller amounts are observed at the Bureau.
These corrections were measured by a method described elsewhere [3] which includes any wideangle scatter from the diaphragm. Measurements of G. H. Aston [17] also confirm that the diaphragm scatter does not contribute more than 0.1 percent to the ionization for several different types of aperture construction with an aperture diameter of approximately $1 \mathrm{~cm}$. The alinement of the defining diaphragm with the X-ray beam remains somewhat critical, even with no scatter diaphragm present. For an aperture of $1 \mathrm{~cm}$ in both diameter and depth, the passage of $\mathrm{X}$-rays from a target $62 \mathrm{~cm}$ away was experimentally found to decrease by about 2 percent when the angle between the aperture axis and the beam direction was changed from 0 to 1.4 degrees. 'Thus this angle must be reduced to a few minutes of arc if the error is not to exceed 0.1 percent.

The procedure for alining the diaphragm with the X-ray beam consists of two steps:

(a) Placing the chamber so that the diaphragm is located approximately at the center of the X-ray beam.

(b) Orienting the chamber so that the axis of the diaphragm aperture is parallel with the rays passing through.

Step (a) can be conveniently done risually with the aid of a fluorescent screen. Step (b) can be accomplished in several ways. If the chamber enclosure has been constructed with sufficient care the rear exit hole will be concentric with the axis of the diaphragm aperture. In that case one can place crossed wires of dense material (e. g., tungsten) over the exit hole and observe their X-ray shadow on a fluorescent screen. If the geometrical precision of the enclosing box is not sufficient to allow this procedure, a substitute diaphragm of brass or steel can be constructed for use in alinement. This should be made with a very long apcrture of small diameter, thus being much more critical to aline than the regular diaphragm. (This need not be the same diameter throughout, but can be made as a tube with a small aperture at each end.) Passing X-rays through this diaphragm and observing their image on a fluorescent sereen will allow the chamber to be properly alined with the beam.

\subsection{Field Distortion}

The length of the collection region is usually fixed by the effective ${ }^{7}$ collector electrode length and by assuring that the limiting lines of force between the collector and the high-voltage electrode are perpendicular to the collector. A similar problem has been solved in standard capacitor design by the use of guard plates. Howerer, the dimensions of the electrode system for an air chamber may be orders of magnitude

\footnotetext{
7 The gaps hetween the collector and guard electrodes are made very small $(<4 \%)$ [18] compared to the collector length, and the effective collector length is the collector length plus one-half of the sum of the two gaps. Note that the entire parallel-plate system must be alined parallel with the $\mathrm{X}$-ray that the entire paralle -plate system must be alined parallel with the $X$-ray
heam, to aroid cosine errors amounting to 0.1 percent for 2.5 degrees of angular misalinement.
} 
larger than for a capacitor. The proximity of a grounded box around the free-air chamber electrodes tends to distort the electric field; however, it is important to make the box as small as possible to minimize its weight. A more efficient system than simple guard electrodes alone is therefore desirable. Aluminum guard wires [19], guard rods [20], or guard strips $[5,21,22]$ have been employed. For parallel-plate chambers these are located, as shown in figure 4 , at the periphery of the plate system, uniformly spaced between the ground and high-voltage plates, and parallel to then. Their potentials are fixed by a voltage divider to give a linear gradient between the plates. The current through the voltage divider should be large compared with the ionization current, but not so large that the power dissipated within the box is excessive. Power dissipation of the order of a few tenths of 1 watt does not cause the temperature of the air in the box to rise appre(iably.

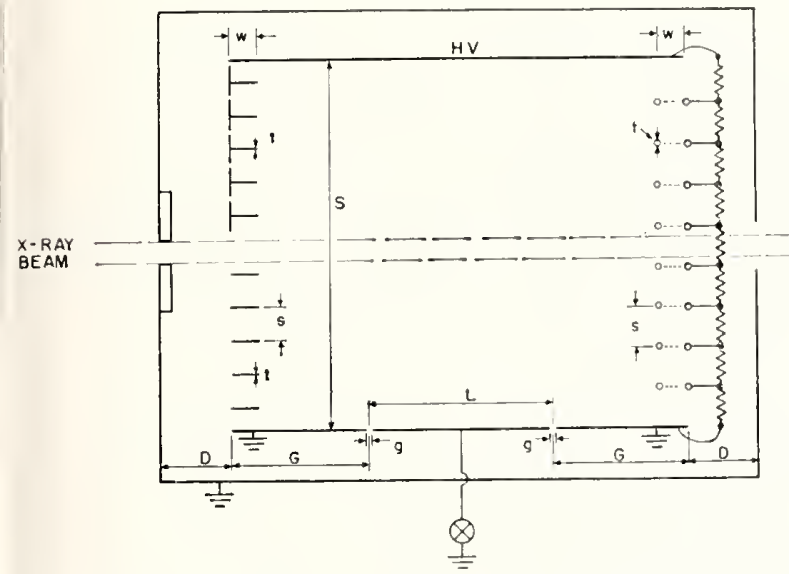

FIGURE 4. Three types of peripheral clectrode systems for guarding the electric field, in a parallel-plate chamber, from the influence of the grounded enclosures.

At the right is shown the double-wire system. Dashed lines indicate the pairs of wires at the same elcetrical potential, fixed by the linear voltage divider. At left are shown parallel strips and T-section electrodes. An opening must be left for the $\mathbf{X}$-ray beam to pass through, to avoid attenuation and scattering. Important dimensions are lettered for reference in the text ( $t$ is the diameter of wire or thickness of the strips).

The adequacy of the guarding is sometimes determined from symmetry considerations. Figure 2 assists in picturing this symmetry for parallelplate geometry. The lines, F, show the proper position for the defining lines of force. Distortion of a grounded box would produce distortion shown schematically by lines $\mathrm{F}^{\prime}$. If the box is placed at the potential of the high-voltage electrode, the defining limes become $F^{\prime \prime}$. For symmetrical conditions (i. e., if the guard electrodes are of the same length and the box is the same distance from each), and for small distortions, the reduction in effective collection length for the first condition should be equal to the increase from the second. Thus the average of the two should correspond to a measurement made with an undistorted field.

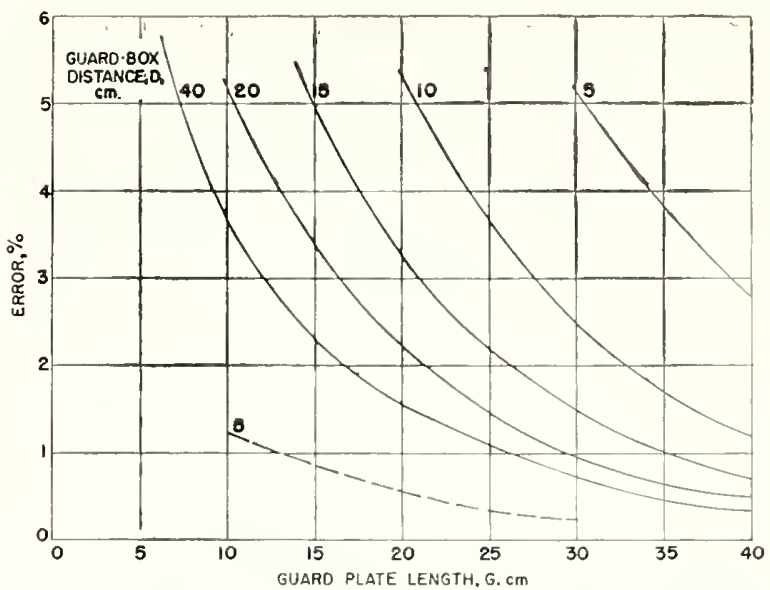

Figure 5. Error in collecting length caused by field distortion in a two-dimensional analog of a parallel-plate freeair chamber.

$L$ (fig. 4) $=10 \mathrm{~cm}, S=40 \mathrm{~cm}, D$ and $G$ variahle. The data are for double guard wires (solid lines) and guard strips (dotted line), with $s=2 \mathrm{~cm}, w=3$ $\mathrm{cm}$, and $t=0.5 \mathrm{~mm}$.

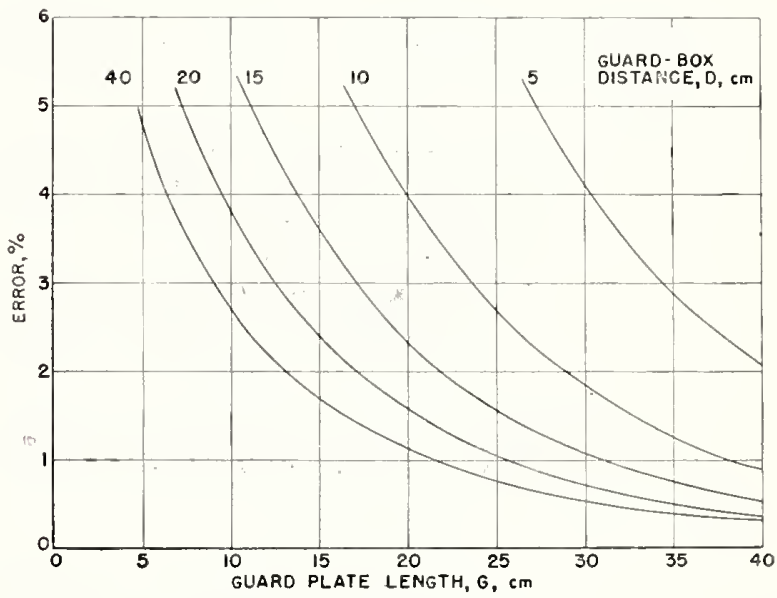

FIGUKE 6. Errot in collecting length caused by field distortion in a two-dimensional analog of a parallel-plate freeair chamber.

$L$ (fig. 4$)=20 \mathrm{~cm}$ ), $\mathrm{S}=40 \mathrm{~cm}, D$ and $G$ variable. The data are for double guard wires with $s=2 \mathrm{~cm}, w=3 \mathrm{~cm}$, and $i=0.5 \mathrm{~mm}$.

These considerations have becn used to determine and correct for field distortion. This has bcen done with actual chambers by mensuring ionization under the two conditions of box potential [23] and has also been used in a resistance analog method [4] for detemining the distortion m two dimensions for a parallel-plate system. Unfortunately, the tro-dimensional results overestimate the three-dimensional distortion, ${ }^{8}$ but they are the only extensive data available on the subject. Figures 5 and 6 show the distortion for In one case considered. Miller and Kennedy [4] predicted a distortion of
about 1 percent whereas the ionization chamber aetually indicated an crror about 1 percent whereas the ionization chamber actually indicated an crror
of 0.3 percent. However, when the third-dimensional effect was eliminated in the ionization chamber, the measured distortion error was 0.7 percent -in fair agreement with the predicted 1 percent. 
two-rlimensional conditions with double wires or strips. The two wires of a given set are in the same plane and connected electrically; the strips have their large dimension in the plane parallel to the electrodes. These data were obtained with a plate separation of $40 \mathrm{~cm}(S$, fig. 4), with $2 \mathrm{~cm}$ $(s)$ between adjacent guard wires in the same plane, with $3 \mathrm{~cm}(w)$ between the two guard wire layers, and with guard wires of approximately $0.5-\mathrm{mm}$ diameter $(t)$. The strips were $t=3 \mathrm{~mm}$ by $w=2$ $\mathrm{cm}$ in cross section. Figure 7 shows the advantage of using larger-diameter wires. 'The distoltion, of course, is unchanged if all of the dimensions are scaled equally. Guard wires may be necessary to reduce absorption in the collimated beam, but the more efficient guard strips should be used outside of this region.

In the design of a parallel-plate free-air chamber, it is recommended that the field distortion be estimated from figures 5, 6, and 7 . A design should be chosen so that the two-dimensional distortion is less than, say, 0.5 percent. The actual distortion should then be determined experimentally on the completed chamber from symmetry considerations. Generally the experimentally determined distortion will be lower than the two-dimensional estimate and independent of photon energy.

In addition to the field distortion eaused by the proximity of the grounded box, there are at least four other ways in which field distortion can arise.

a. Distortion near guard wires or strips.

The guard wires or strips must be sufficiently far from the collecting region so as not to individually distort the field there. In one particular arrangement [24], a distance of about 10 times the guard-strip separation secms to be adequate. This means that $(G-W)$ (fig. 4) should be at least 10 times.

b. Misalinement of the collector plate and adjacent guard plates.

For a parallel-plate chamber, these plates should be coplanar. If they are not, the collector will receive too much ionization if it projects toward the X-ray beam, or too little if it is recessed behind the plane of the guard plates. For $L=10 \mathrm{~cm}$ and $g=0.9 \mathrm{~mm}$, the error in ionization current collected is approximately 0.1 pereent per 0.025 mm of misalinement. This was found to be independent of $S$ over the observed range of 6 to 10 cm, and hence may be assumed to be caused by a local fickl disturbance in the immediate region of the junction of the collector and guard plates. The magnitude of this error should be inversely proportional to $L$ for a constant value of $g$, and independent of the potential on the high-voltage plate.

c. Contact potential difference between guard plates and collector electrodes.

If the work functions of the surfaces of the collector and guard plates are appreciably different, a potential difference sufficient to clistort the field will result across the gap between them. The.

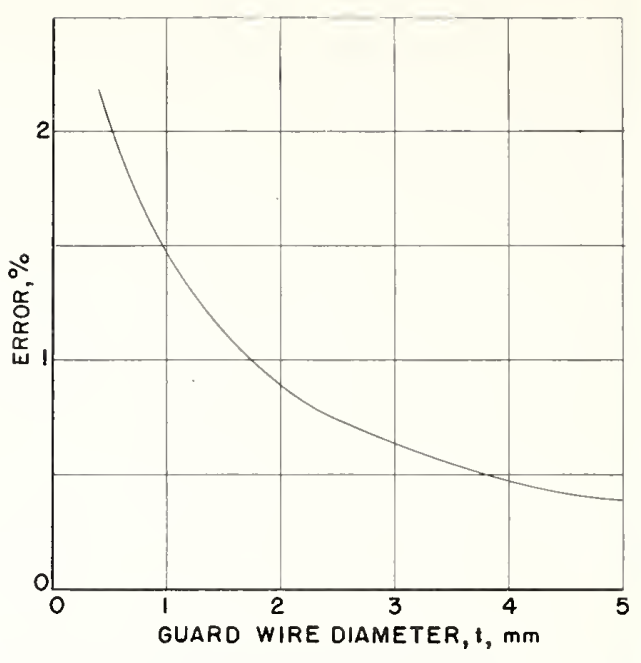

HIGURE 7. Effect of guard-wire diameter, $t$, on the errors shown in figures 5 and 6 .

$S$ (fig. 4) $=40 \mathrm{~cm}, L=10 \mathrm{~cm}, G=40 \mathrm{~cm}$. single guard wires with $s=2 \mathrm{~cm}$.

collector will receive more or less than the correct ionization eurrent, depending on the polarity of the potential on the high-voltage plate. This effect has been observed at the Bureau even when the collector and guard plates of an experimental parallel-plate chamber were of the same material (aluminum). Coating these plates with colloirlal graphite removed the effect, which was causing an error of several tenths of 1 percent. Most of the effect disappeared when only a 1-cm-wide strip on each plate, adjacent to the gap, was coated, which tends to confirm further the nature of the effect as being contact potential difference between the plate surfaces neal the gap. If this error is present in a chamber, it shows up as a difference in the measured ionization when the polarity of the potential on the high-voltage plate is reversed. The magnitude of the error' is reduced by increasing the high-voltage potential. Thus for sufficiently high potential to satisfy saturation requirements, the contact potential error becomes small and the ionization currents measured with the two polarities approach their average value [25].

d. Externally imposed potential difference between collector and guard electrodes.

This causes distortion similar to that of contact potential difference (sec section 3 ).

\subsection{X-ray Scattering and Electron Losses}

The collimated beam of X-rays within the chamber interacts with the air to produce highspeed clectrons and secondary photons (Compton and fluorescent). These secondary photons may in turn produce high-speed electrons within the measuring volume. However, a measurement in roentgens requires a determination of the ionization from the high-speed electrons produced by the collimated photons alone. Thus it is well to consider separately the ionization from the two 
mechanisms (electron and secondary photon). Both ionization densities are functions only of the radial distance from the photon beam. ${ }^{9}$ However, the gain of ionization from the secondary photons tends to compensate for the loss of ionization from the ligh-speed electrons due to insufficient plate spacing.

Figures 8, 9, and 10 show the perentage of electron ionization loss, $E_{\tau}$, beyond a radius, $r$, from the photon beam, computed for a zero diameter of beam (air at $26^{\circ} \mathrm{C}$ and $760 \mathrm{~mm} \mathrm{Hg}$ ). ${ }^{10}$ Figures 11, 12, and 13 show the electron contribution per radius increment, $\Delta E / \Delta r$, at different inner radii. Table 2 shows the umwanted secondary photon contribution, $S_{r}$ (within a radius, $r$ ), in percentage of the total electron contribution (i. e., ionization resulting from complete utilization of the clectrons produced by primary photons).

8 It is assumed that electronic enuilibrium exists. See section 2.5 for distance between aperture and eollector for eleetronie equilibrium.

10 For other pressures and temperatures, the distanees given should be sealed to the same mass of air.

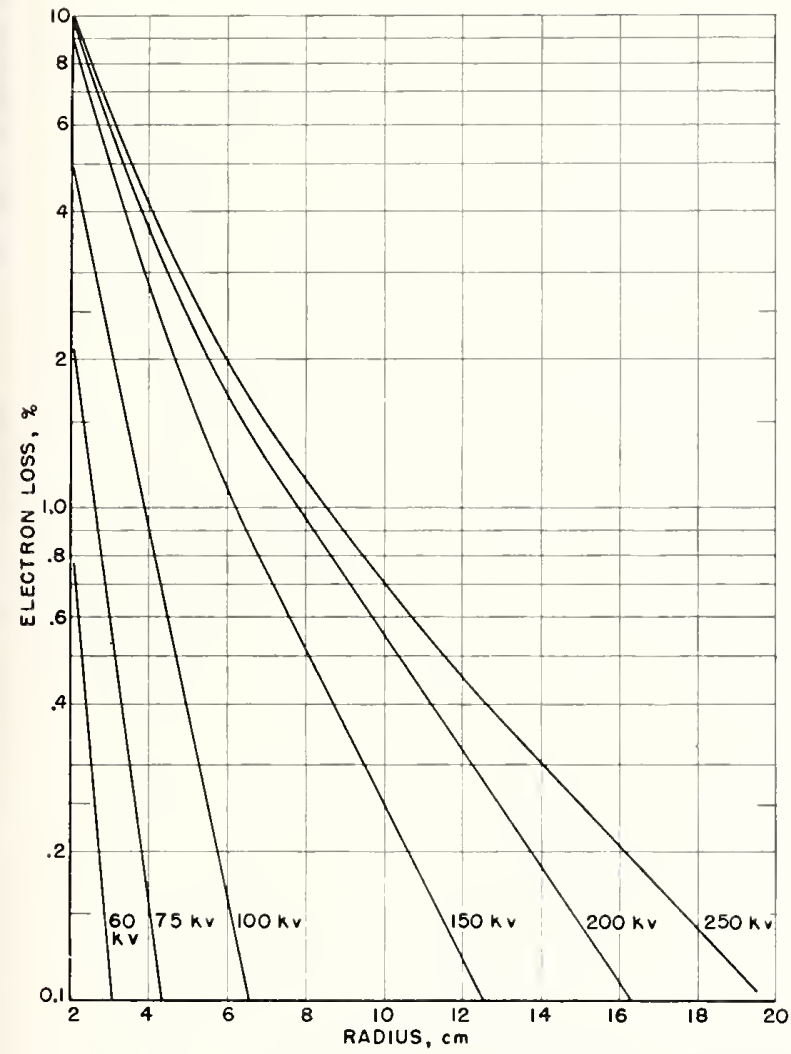

FIGURE 8. Loss of electron-produccd ionization (in percentage of total electron ionization) beyond differcnt radii from a zero-diameter beam of constant potential $X$-rays.

The X-ray potentials were 60 and $75 \mathrm{kv}$ with zero added filter, $100 \mathrm{kv}$ with $1 \mathrm{~mm} \mathrm{Al}$ added filter, $150 \mathrm{kv}$ with $0.23 \mathrm{~mm} \mathrm{Cu+1} \mathrm{mm} \mathrm{Al,} 200 \mathrm{kv}$ with 0.5 $\mathrm{mm} \mathrm{Cu+1} \mathrm{mm} \mathrm{Al,} \mathrm{and} 250 \mathrm{kv}$ with $1 \mathrm{~mm} \mathrm{Cu+1} \mathrm{mm} \mathrm{Al.} \mathrm{The} \mathrm{X-ray} \mathrm{tube}$ had an inherent filtration of approximately $3 \mathrm{~mm} \mathrm{Al}$.
As this contribution varies very slowly with the radius, 5-em increments have been taken. The secondary radiation contribution is also for a zero-diameter beam. The use of these data to compute the ionization excess or deficiency for a particular design is illustrated later.

TABLE 2. Secondary photon contribution

\begin{tabular}{|c|c|c|c|c|c|c|c|c|c|}
\hline \multirow{2}{*}{ Radius } & \multicolumn{9}{|c|}{ a Seeondary photon eontribution, $s_{r}$} \\
\hline & 60 & 75 & 100 & 150 & 200 & 250 & 300 & 400 & 500 \\
\hline $\begin{array}{r}c m \\
5 \\
10 \\
15 \\
20 \\
25\end{array}$ & $\begin{array}{r}k v \\
6.14 \\
.32 \\
.55 \\
.79 \\
1.02\end{array}$ & $\begin{array}{r}k v \\
0.14 \\
.32 \\
.55 \\
.79 \\
1.02\end{array}$ & $\begin{array}{r}k w \\
0.13 \\
.30 \\
.51 \\
.74 \\
95\end{array}$ & $\begin{array}{r}k v \\
0.11 \\
.25 \\
44 \\
.63 \\
81\end{array}$ & $\begin{array}{r}k v \\
0.10 \\
.23 \\
40 \\
56 \\
75\end{array}$ & $\begin{array}{c}k l \\
0.09 \\
.21 \\
.36 \\
.53 \\
64\end{array}$ & $\begin{array}{r}k v \\
0.08 \\
.19 \\
.33 \\
.47 \\
61\end{array}$ & $\begin{array}{r}h v \\
0.06 \\
.17 \\
29 \\
42 \\
54\end{array}$ & $\begin{array}{r}k v \\
0.06 \\
.17 \\
.29 \\
.42 \\
54\end{array}$ \\
\hline $\begin{array}{l}30 \\
35 \\
40\end{array}$ & $\begin{array}{l}1.23 \\
1.43 \\
1.62\end{array}$ & $\begin{array}{l}\text { 1. } 23 \\
\text { 1. } 43 \\
1.62\end{array}$ & $\begin{array}{l}1.15 \\
1.33 \\
1.51\end{array}$ & $\begin{array}{r}.94 \\
1.14 \\
1.30\end{array}$ & $\begin{array}{r}.90 \\
1.05 \\
1.19\end{array}$ & $\begin{array}{r}.82 \\
.95 \\
1.08\end{array}$ & $\begin{array}{l}74 \\
86 \\
97\end{array}$ & $\begin{array}{l}66 \\
.76 \\
86\end{array}$ & $\begin{array}{l}66 \\
.76\end{array}$ \\
\hline
\end{tabular}

a Pereentage of total eleetron contribution for filtrations listed in figures 8 and 10 .

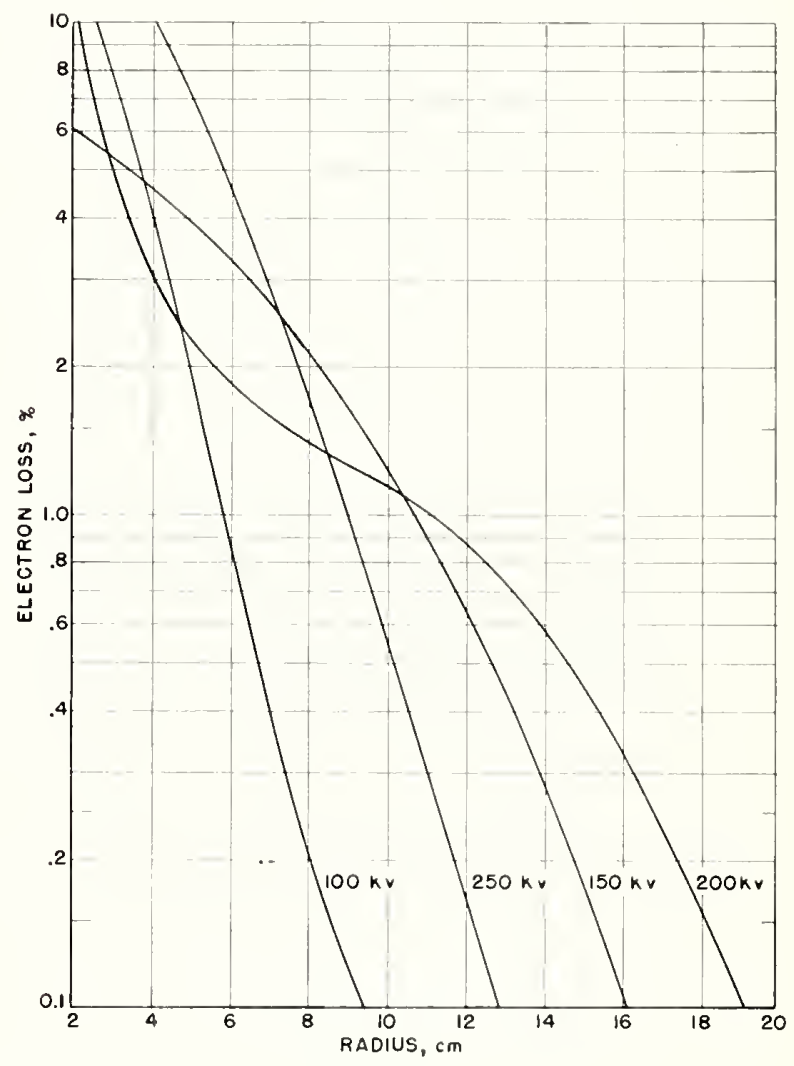

Figure 9. Loss of electron-produccd ionization (in percentagc of total electron ionization) beyond different radii from a zero-diameter beam of constant potential X-rays.

The X-ray potentials were $100 \mathrm{kv}$ with $0.53 \mathrm{~mm} \mathrm{~Pb}$ added filter, $150 \mathrm{kv}$ with $1.53 \mathrm{~mm} \mathrm{Sn}+4.0 \mathrm{~mm} \mathrm{Cu}, 200 \mathrm{kv}$ with $0.7 \mathrm{~mm} \mathrm{~Pb}+4.0 \mathrm{~mm} \mathrm{Sn}+0.59$ $\mathrm{mm} \mathrm{Cu}$, and $250 \mathrm{kv}$ with $2.7 \mathrm{~mm} \mathrm{~Pb}+1.0 \mathrm{~mm}$ Sn+0.59 mu Cu. 


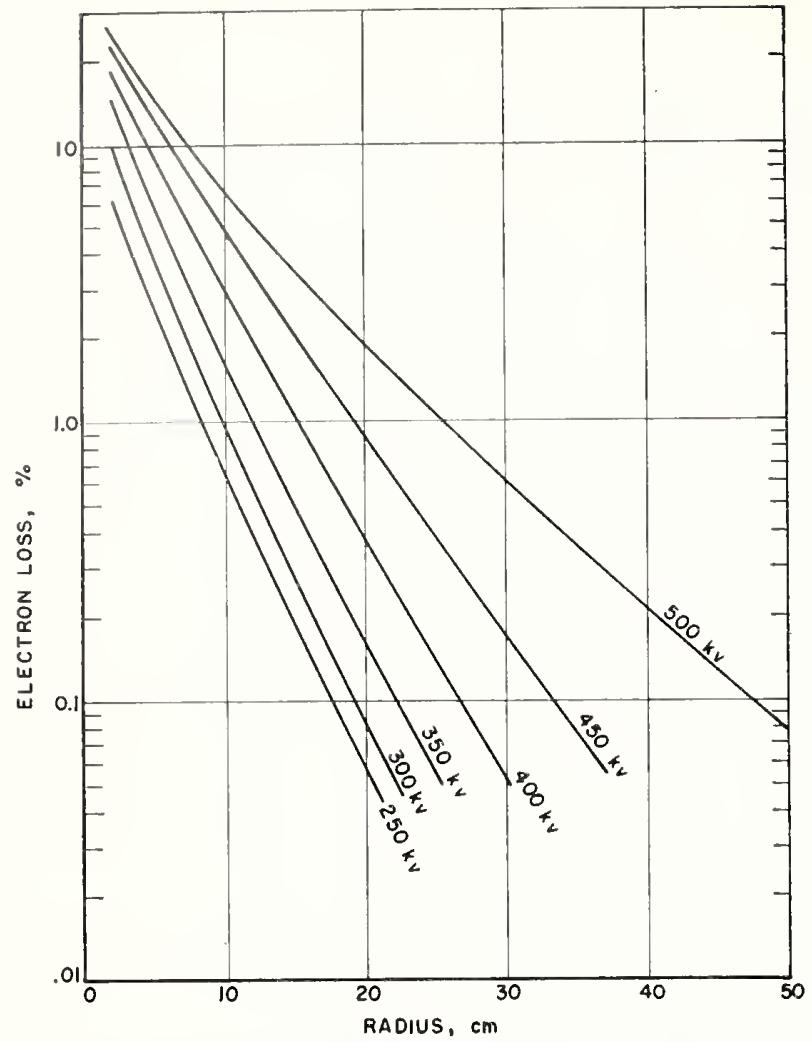

FIGURE 10. Loss of clectron-produced ionization (in percentage of total elcctron ionization) beyond different radii from zero-diameter X-ray beams of the constant potentials indicated.

The inherent filtration of the beam was approximately $3 \mathrm{~mm} \mathrm{Cu}$.

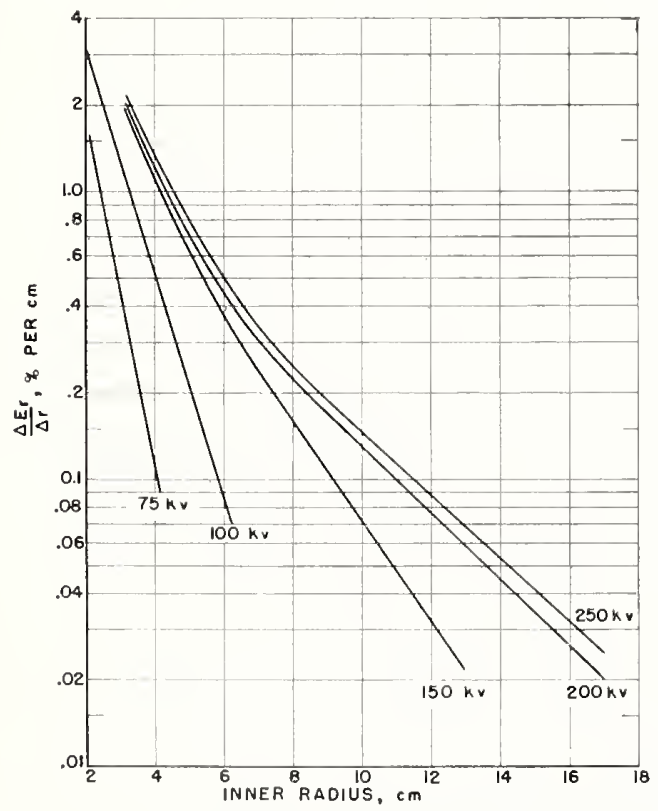

Figure 11. Loss of clcctron-produced ionization per centimetcr for the indicated constant potcntial X-ray bcams and the filtrations given in figure 8 .

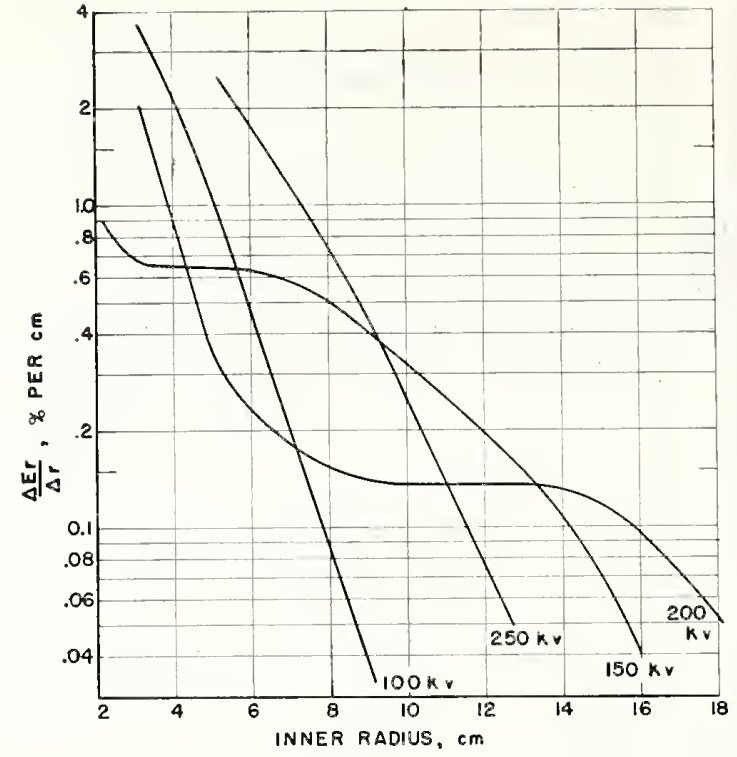

FIGURE 12. Loss of electron-produced ionization per centimeter for the indicated constant potential X-ray beams and the filtrations given in figure 9.

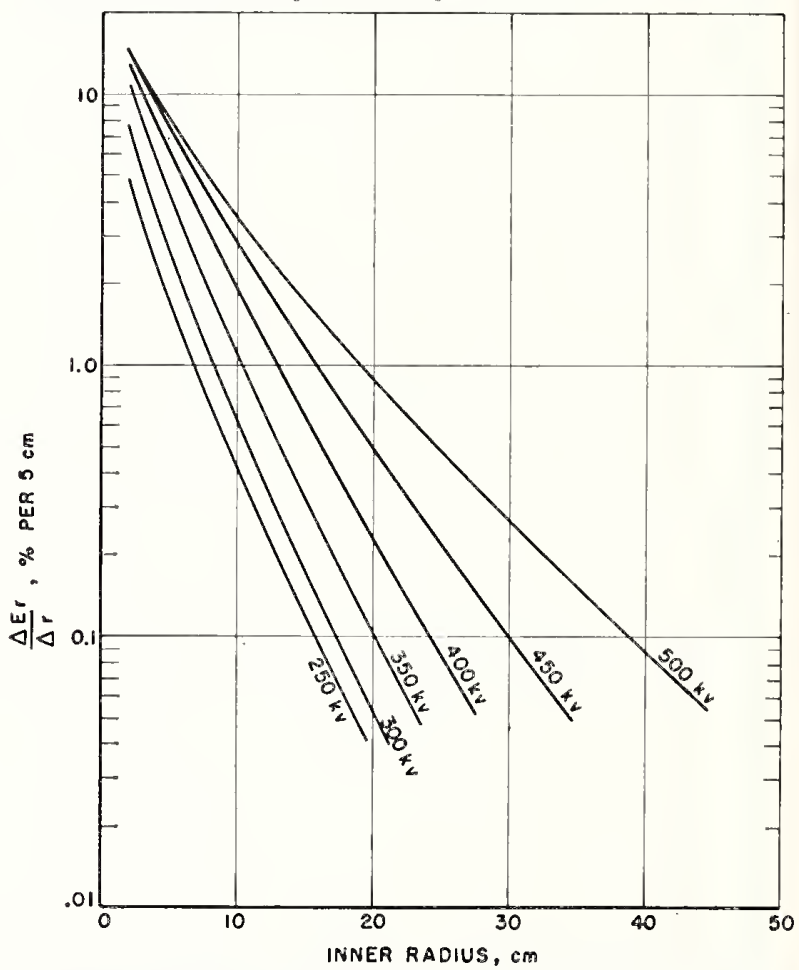

FIGURE 13. Loss of electron-produced ionization per $5 \mathrm{~cm}$ for the indicated constant potential $X$-ray beams and an inherent filtration of approximately $3 \mathrm{~mm} \mathrm{Cu}$.

\subsection{Aperture-to-Collector Distance}

The distance, $l$ (fig. 2), between the aperture and the front edge of the collector, must be sufficient for electronic equilibrium. Figure 14 shows the minimum distance required for electronic equilibrium at difierent tube potentials with about $3 \mathrm{~mm}$ of copper filtration, as determined experimentally [5]. Also shown is the distance 


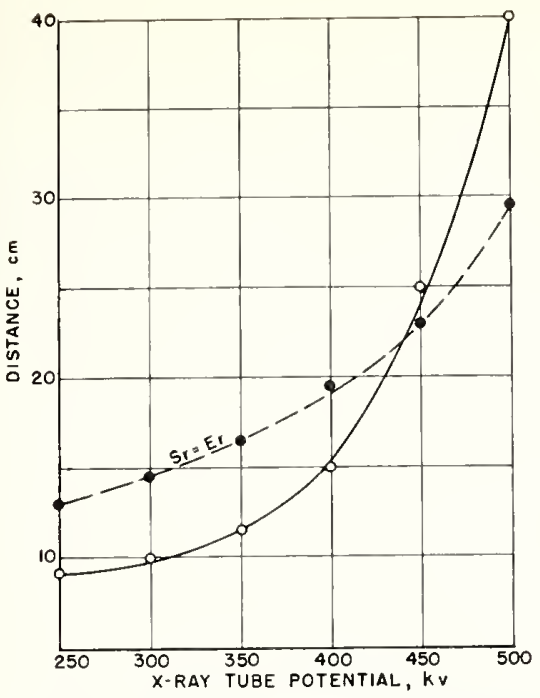

Fíure 14. Criteria for electronic rquilibrium.

Air distance reculired for electronic equilibrium (solid curve) and radius at which primary electron-produced ionization loss, $E_{r}$, is just compensated by sccondary photon-produced ionization gain, $S_{r}$, (dotted curve) for X-rays having approxinately $3 \mathrm{~mm} \mathrm{Cu}$ filtration.

equal to that radius at which the electron ionization loss is just compensated by the secondary photon contribution, $S_{r}=E_{r}$, which has been sliggested [5] as a working criterion up to $400 \mathrm{kv}$. It is evident that this criterion is more than adequate in its $\mathrm{kv}$ range, but that $l$ should be at least $25 \mathrm{~cm}$ with $450 \mathrm{kv}$ and $40 \mathrm{~cm}$ with $500 \mathrm{kv} .{ }^{11}$

\subsection{Losses From Ion Recombination}

The definition of the roentgen requires that all of the ionization produced by electrons originating in the defincd volume be collected. As the collecting potential is increased from a very low value, the ionization current collected increases rapidly, and then tends to level off. However, it does not become completely independent of voltage but rather approaches the full saturation level asymptotically. Hence, it is necessary to establish a practical working criterion for determining the saturation current without going to extremely high collecting potentials. The criterion most frequently encountered in the literature is simply that the voltage be large enough so that the sensitivity of the electrometer system used is insufficient to detect any voltage dependence of the current as the voltage is increased further. This is somewhat indeterminate unless the electrometer current-sensitivity is further specified and the range of voltages given. For present purposes, one might make use of a criterion requiring that a decrease in potential to one-half the operating potential should not decrease the ionization by more than 0.1 percent. This is a rather stringent requirement, and sometimes cannot be achieved with the maximum voltage available.

There is somc evidence [26] that a plot of $1 /$

11 Using a distance of $29.5 \mathrm{~cm}$ (where $S_{\mathrm{r}}=E_{\mathrm{r}}$ ) instead of $40 \mathrm{~cm}$ would cause an error of approximately 0.3 percent. (ionization current, $i$ ) versus $1 /$ (collecting potential, $T$ ) can be extrapolated to the $1 / T^{r}=0$ axis to obtain the full saturation current. If the data are earried to large enough potentials, the curve will become nearly linear ${ }^{12}$ and the extrapolation therefore straightforward. Of course, for greatest aceuracy, the free-air chamber should be operated at sufficiently large potentials so that the extrapolation does not exceed a few tenths of 1 percent in ionization current. A gradient of $250 \mathrm{v} / \mathrm{cm}$ has been found adequate for dose rates ordinarily encountered $(<50 \mathrm{r} / \mathrm{min})$ and with an X-ray beam diameter (at the collector) of about $1.6 \mathrm{~cm}$. Decreasing the beam diameter lowers the voltage required to achieve a given degree of saturation, but of course also decreases the current output of the chamber for a given dose rate.

It will be useful to recognize that if the applied roltage, say $V_{1}$, is large enough so that $V_{1} / 2$ still lies on the final linear portion of the $1 / i$ versus $1 / V$ plot, then the decrease in $1 / i$ observed in passing from $V_{1} / 2$ to $V_{I}$ should equal the decrease obtained by extrapolation from $V_{1}$ to $V=\infty$. Thus the alternative criterion (requiring that halving the voltage should not decrease the current by more than 0.1 percent) places one within 0.1 percent of the full saturation current, which can then be immediately obtained by adding the observed decreasc.

\subsection{Air Attenuation Corrections}

As indicated in the discussion of figure 2 , the ionization collected is a measure of the intensity of the beam in the collection region. However, it is usually desired to know the exposure dose rate at the diaphragm. For this computation, it is necessary to know the air absorption in distance $d$, as has been mentioned previously. Figure 15 shows the percentage of absorption per meter experimentally determined for X-rays of various kilovoltages and with various filtrations.

I2 Some experimental evidence obtained at the Bureau, both with a stand ard free-air chamber and a cavity-ty"pe chamber, seems to verify this.

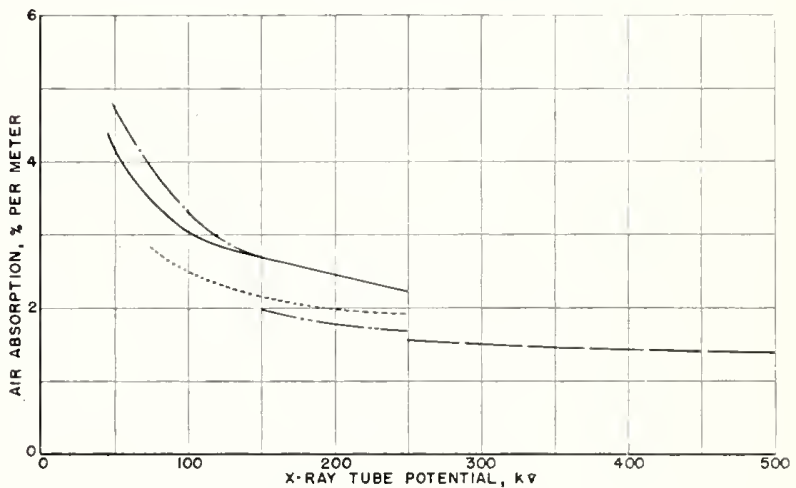

FIGURE 15. Air absorption coefficient for corstant potential $X-$ ray beams.

The inherent filtrations are $3 \mathrm{~mm} A 1$ (dot-dash eurve), $1 \mathrm{~mm} \mathrm{Al}$ (solid curve), $0.25 \mathrm{~mm} \mathrm{Cu}+1 \mathrm{~mm} \mathrm{Al}$ (dotted curre), $1 \mathrm{~mm} \mathrm{Cu+1} \mathrm{mm} \mathrm{Al} \mathrm{(dasl-}$ dot-(lot curve), and a total filtration of anproximately $3 \mathrm{~mm} \mathrm{Cu}$ (dash curve). 


\subsection{Shielding Against Stray Radiation}

A shield (box of fig. 2) around the electrode system is used to reduce stray ladiation to a negligible amount compared to the radiation admitted through the aperture. While the radiation beam that strikes the front of this box is generally much smaller than the area of the front face, it is usual to assume that the entire collecting volume (plate spacing times collector height times collector width in a parallel-plate chamber) ${ }^{13}$ can produce ions from this stray radiation. This ionization must be a negligible amount, that is, not more than 0.1 percent of the radiation admitted through the aperture. Thus the transmission allowed by the shielding in the front of the box must not exceed 0.001 times the aperture area divided by the product of the plate height and the plate spacing. Lead, because it readily absorbs this radiation, is usually used for shielding. Figure 16 [27] gives transmission curves for the X-ray potentials of interest here. The sides and back of the box may also require some shielding. It is difficult to say what amount of scattered radiation might strike these surfaces, but if no other data are available, one may assume a thickness requirement equal to one-quarter of that for the front face.

${ }_{13}$ For a eylindrical ehamber, the collecting area is essentially the crosssectional area enclosed by the onter electrode.

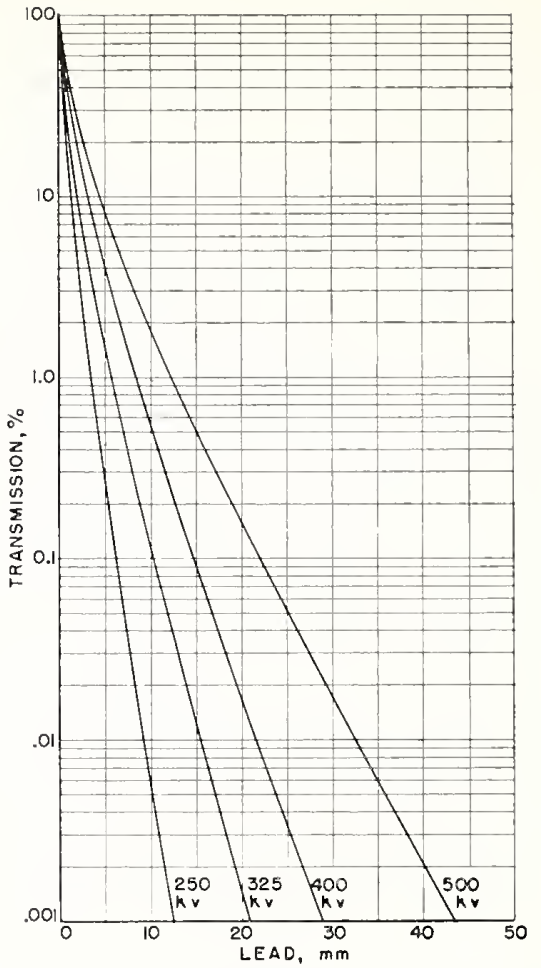

Firure 16. Broad-beam transmission curves in lead for constant potential $\mathrm{X}$-ray beams with an inherent filtration of approximately $3 \mathrm{~mm} \mathrm{Cu}$.

\section{Current or Charge Measurement}

Several different types of electrometers have been used to measure the ionization current or charge, but each must be connected and operated in such a way as to maintain the collector electrode at very nearly the same potential ${ }^{14}$ (usually ground) as the guard plates [25]. As pointed out earlier, this requirement on the potential is necessary to reduce otherwise excessive field distortion near the gap between the collector and guard plates. Thus the electrometer itself must be sufficiently sensitive to indicate significant differences of potential $(\sim 0.1 \mathrm{v})$ between the collector and guards. ${ }^{15}$ Most types of electrometers fulfill this requirement.

Figure 17 shows two electrometer circuits used for free-air chamber ionization measurements ${ }^{16}$ [31]. Both employ the electrometer as a null detector, making a voltage calibration of its scale unnecessary, and eliminating the collection of charge on the stray capacitance of the system.

14 Some electrometers, such as the ribrating-reed type made by Applied Physies Corp. of Pasadena, Calif., maintain the potential of the collector plate within a few millivolts of zero potential, regardless of the indication of the meter on the electrometer.

$15 \mathrm{~A}$ difference in potential of $0.2 \mathrm{v}$ between collector and guard plates in the present NBS standard chamber has been observed to produce an error in the measured ionization of about 0.1 percent when the collecting field was of the order of $100 \mathrm{v} / \mathrm{cm}$.

16 The potentiometer connection to ground shown in figures $17 \mathrm{a}$ and $17 \mathrm{~b}$ should be connected insterd to the "G" terminal on the electrometer if the vibrating-reed type of the Applied Physies Corporation is used. The intermal capacitor $\mathrm{C}_{\mathrm{c}}$ of this electrometer does not enter into the ealculation of current for either of these circuit arrangements.
The electrometer need only be sensitive enough to allow the compensating voltage to be adjusted with the required accuracy $(<0.1$ percent) and to fulfill the aforementioned field distortion requirement.

The resistor method shown in figure 17 a continuously measures the instantaneous current
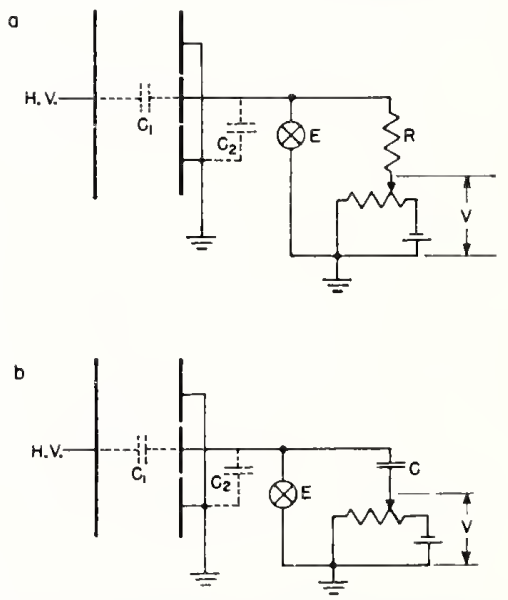

FIGURE 17. Electrical circuits for measuring the ionization current while maintaining the collector electrode near zero polential during $X$-ray exposure by means of the electrometer, $E$. 
from the chamber. 'This current produces a potential drop across a known resistance, and this IR drop is balanced by a variable voltage source. In order to obtain the required accuracy, it is convenient to measure the balancing potential with a potentiometer. For low balancing voltages, the potentiometer itself may serve as the voltage source. Note that the ionization current passes through the variable voltage source on its way to ground; hence the voltage source must have a very small resistance compared to that of the calibrated resistor.

Most resistors now commercially available have an appreciable voltage coefficient of resistance [28] and sometimes have erratic behavior for potentials greater than $1 \mathrm{v}$. Therefore it is wise to use several different resistors and a small voltage range for each, rather than a single resistor and a large range of voltage to cover the desired ionization current range. Figure 18 shows the design of a convenient resistor "turret" for housing and switching a series of 12 resistors. While this turret was designed for use with a particular electrometer, the design may be adapted readily to other types. With such a turret, it is possible to cover adequately 5 decades of current and still keep the voltage across the resistor to the order of $1 \mathrm{v}$. Even the best of commercial resistors now available in the $10^{8}$ - to $10^{12}$-ohm range sometimes show erratic changes in resistance of as much as 1 percent [28]. While these can be calibrated to the order of 0.1 percent, frequent checking is required to maintain that accuracy. Thus this method of measuring the ionization current leaves something to be desired.

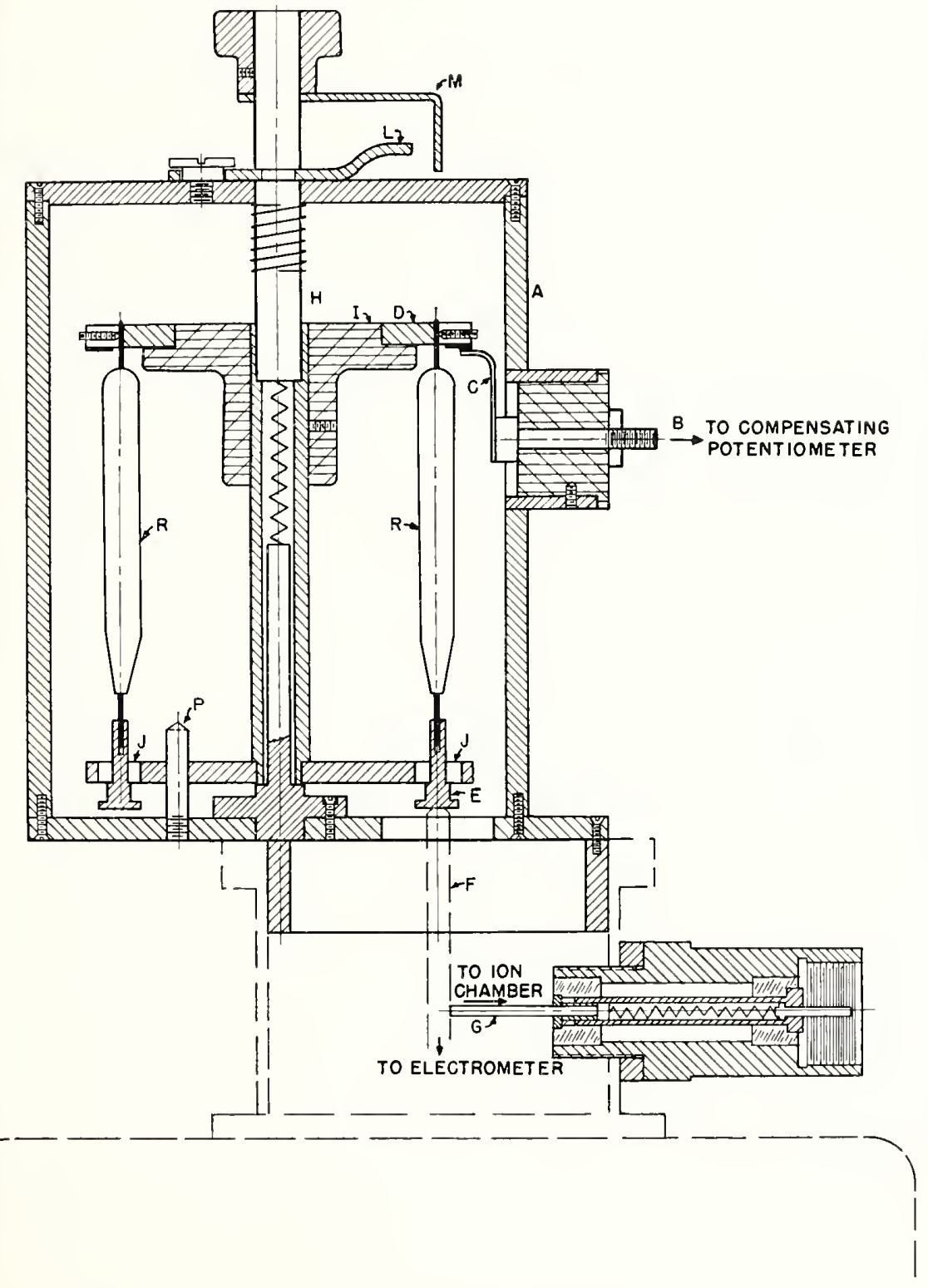

Finure 18. Sectional view of resistor turret.

Resistors $\mathbf{R}$ are mounted on a rotor which ean be lifted and turned to any one of 12 positions. The resistor assembly is housed in a grounded metal case, A. One electrical lead, B, connects to one end of each of the resistors, $\mathrm{R}$, by means of a spring, $C$, and metal ring, 1$)$. The latter is insulated by 1 from the grounded metal axle, $H$. The other end of each resistor is insulated by J from the bottom plate. ln order to switch to another resistor, the arm, $\mathrm{L}$, is moved aside so that the resistor assembly can aside so that the resistor assembly call
move npward in the housing, A, until the bottom plate clears the fixed pin, $P$. The resistor assemhly is then rotated until the arm, $M$, is over the proper resistor marking on $\mathrm{A}$ and the assembly is pushed down so that P goes through the proper hole in the bottom plate. The assembly is locked in place by $\mathrm{L}$. Connection to the resistor is made through the spring-loaded pin, $\mathrm{F}$. 
Figure $17 \mathrm{~b}$ shows a current-measuring circuit incorporating a charge-compensating capacitor for maintaining the collector at ground potential during a measurement. This method, of course, integrates the current over a measured time interval. Figure 19 shows the design of a modified commercial capacitor which has been found to maintain its calibration to better than 0.1 percent over a number of years. 'The connections can be modified to fit the electrometer and calibration device with which the capacitor is to be used. In this design the dielectric is air, so it is possible to calibrate such capacitors on an a-c bridge (operating at, say, $1,000 \mathrm{cps}$ ), which is usually more convenient than a d-e calibration. Such capacitors can be calibrated readily to better than 0.1 pereent and are easily removed from the electrometer for recalibration when necessary. Capacitor's are not limited to such small voltages as the
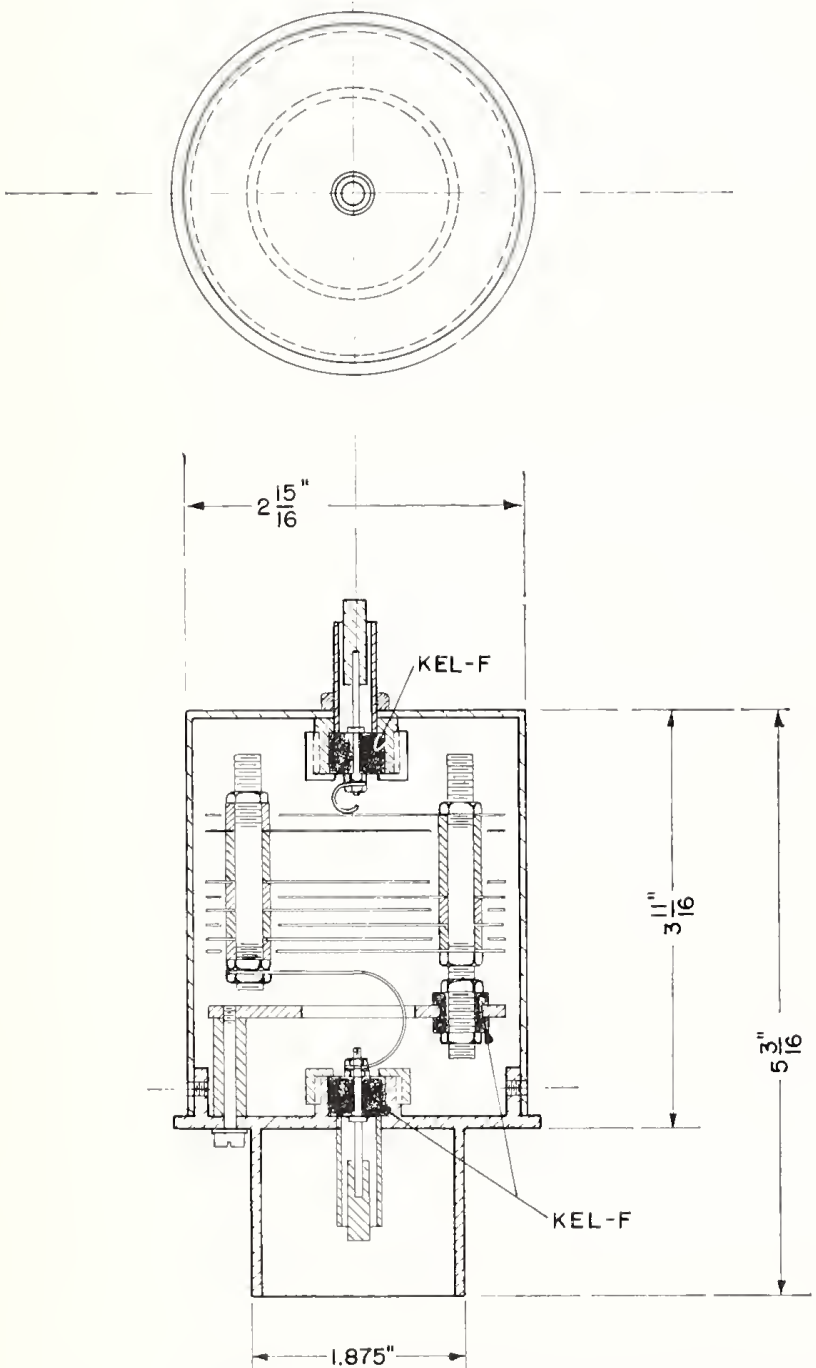

Finure 19. Sectional view of capacitor for charge measurewhent.

The ease is to be grounded during use. resistors. Potentials of over $200 \mathrm{v}$ have been used with impunity.

The high-voltage supply used for the collecting potential must be sufficiently stable to have a negligible effect on the current measurements made with the electrometer. The severity of this requirement can be judged by referring to figure 17. $C_{1}$ represents the capacitance between the collector and the high-voltage plate. For a parallel-plate arrangement, if the collecting plate has an area of $a \mathrm{~cm}^{2}$ and is separated from the high-voltage plate by a distance $S \mathrm{~cm}$, the capacitance between the two is approximately 0.0885 $(a / S) \mu \mu \mathrm{f}$. Thus for $a$ equal to $200 \mathrm{~cm}^{2}$ and $S$ equal to $20 \mathrm{~cm}$, the capacitance $C_{1}$ will be of the order of $1 \mu \mu \mathrm{f}$. $C_{2}$ represents the stray capacitance from the collector and its connections (including the electrometer) to ground. For purposes of illustration this can be taken as $100 \mu \mu \mathrm{f}$, although its value will depend strongly upon the individual arrangement of conductors. If the collecting potential suddenly fluctuates by an amount $\Delta V_{H}$, the collecting clectrode in figure 17 a will vary in potential by an amount

$$
\Delta V_{C}=\frac{C_{1}}{C_{1}+C_{2}} \Delta V_{H}
$$

or about $0.01 \Delta V_{H}$ in the example given above. Thus, if $\Delta V_{H}$ is $1 \mathrm{v}$, the electrometer will indicate a fluctuation of about $0.01 \mathrm{v}$. For the usual balancing potentials used in the resistor method $(\approx 1 \mathrm{v})$, this amounts to a 1 percent fluctuation. If such fluctuations occur frequently during a measurement, it becomes very difficult to adjust $V$ to the proper value within 0.1 percent, because the null position of the electrometer is not well defined. As the collecting potential usually amounts to several thousand volts, the requirement that it be stable to better than $1 \mathrm{v}$ is very severe.

The charge-balancing method shown in figure $17 \mathrm{~b}$ is somewhat less restrictive on the collecting potential, because $C_{2}$ is increased by the addition of the compensating capacitor $C$. This usually has a value of several hundred $\mu \mu \mathrm{f}$, so that $\Delta V_{C}$ is of the order of $0.001 \Delta V_{H}$. This may be considered as another advantage of the capacitor method over the resistor method. Power supplies sufficiently stable to fulfill this requirement are available commercially. An alternative method for compensating for the voltage fluctuations rather than eliminating them has also been described by De Bitetta [29].

Because of the small order of magnitude of the currents involved. only the highest-quality insulating materials are suitable for supporting the collector electrode and insulating the connecting lead to the electrometer. 'The insulator' surfaces must be dust-free and perfectly clean to avoid leakage troubles. Amber, polystrvene, polyethylene, Teflon, and "Kel-F" are all good, although the polyethylene is too flexible for use in rigidly supporting the collector. Polystyrene is usually cleaned by machining but the other materials may be cleaned with absolute alcohol. 


\section{Examples}

In order to test the over-all adequacy of the data just presented and to provide a guide for heir use, it is worth while to use these data in determining the corrections to be applied to two hambers, and to compare these corrections with he experimental comparison between them. For such a comparison, it is well to consider the ntercomparison of two very dissimilar chambers so that their corrections are very different. The alibration of the Swedish portable chamber with the NBS standard [7] will be used as an example. Figures 20 and 21 show sectional plan views of the Swedish and NBS chambers respectively.

The dose rate of an X-ray beam for saturation conditions may be computed from the equation

$$
\begin{aligned}
\frac{\mathrm{r}}{\sec }=\left(\frac{3 \times 10^{9}}{A L}\right) & \left(\frac{T}{273.2}\right)\left(\frac{760}{P-0.238 P_{1}}\right) \\
& \left(\frac{100}{100+K}\right)\left(\frac{100}{100+f}\right)\left(C \frac{\Delta V}{\Delta t}\right) e^{+\mu d}
\end{aligned}
$$

where

$A$ is the area of the defining aperture (in $\mathrm{cm}^{2}$ ),

$L$ is the collector length from gap-center to gapcenter (in cm),
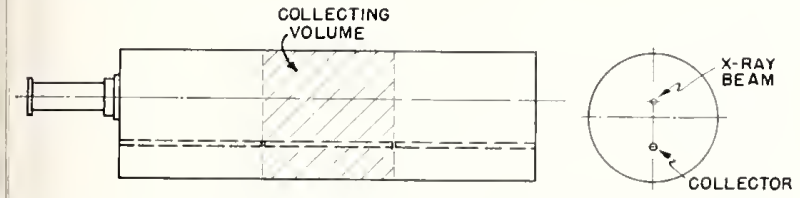

SWEDISH CHAMBER

Figure 20. Sectional view of Swedish portable free-air chamber.
$T$ is the temperature of the air in the collection region (in ${ }^{\circ} \mathrm{K}$ ),

$P$ is the pressure of the air in the collection region (in $\mathrm{mm} \mathrm{Hg}$ ),

$P_{1}$ is the pressure of water vapor in the collection region (in $\mathrm{mm} \mathrm{Hg}$ ),

$K$ is the algebraic sum of the deficiency of electron and excess of sceondary ionization collection (in percentage of total electron ionization),

$\mu$ is the air absorption coefficient (in $\mathrm{m}^{-1}$ ),

$d$ is the distance from the plane of definition in the aperture to the center of the collecting region (in $\mathrm{m}$ ),

$f$ is the percentage gain of ionization due to field distortion,

$C$ is the capacitance upon which the charge is collected (farad),

$\Delta V / \Delta t$ is the rate of change of the balancing potential on the charge-measuring instrument (v/sec).

The two chambers were set up on a track perpendicular to the beam so that each could be moved in turn into the fixed X-ray beam. The' limiting aperture of each was at the same distance from the target (approximately $1.5 \mathrm{~m}$ ). Each chamber was alined visually and fluoroscopically. The temperature of the air in the boxes was measured to the nearest $0.1^{\circ} \mathrm{C}$ cluring the intercomparison. ${ }^{17}$ The air and vapor pressure were assumed to be the same during the measurement because both of the boxes were open to the room air. Independent comparisons were made of the capacitances, $C$, by a charging method, and of the

${ }_{17}$ Differences of as much as $0.5^{\circ} \mathrm{C}$ were observed between the temperatures of the air in the two boxes at the same time.

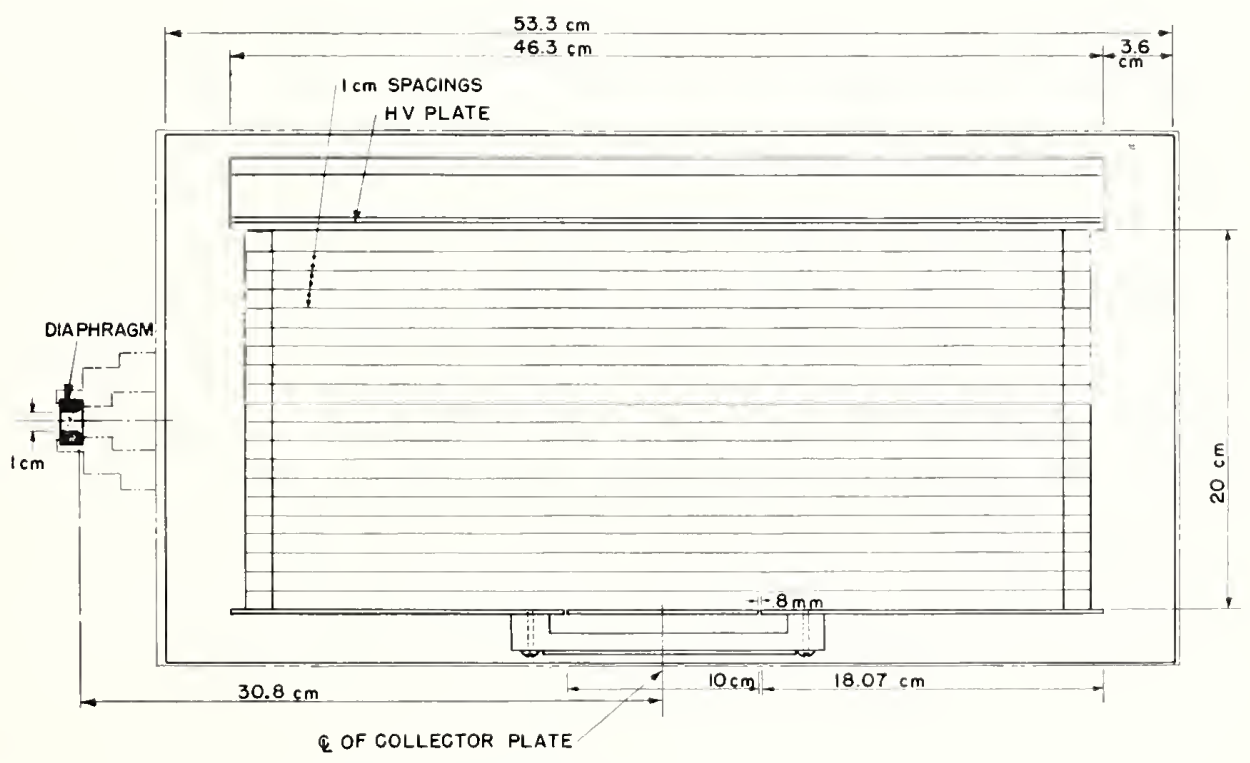

Figure 21. Sectional view of NBS free-air chamber.

The collector plate height is $26.8 \mathrm{~cm}$. 
diaphragm areas, $A$, by an ionization method with one of the chambers. The ratio of $C$ 's agreed to within 0.02 percent with the ratio of the value certified by the Swedish laboratory and by the Bureau. The ratio of $A$ 's could not be compared with the areas computed from tha measured diameters because of a slight coning of the Swedish diaphragm. Therefore the ionization ratio was accepted. The potentiometers used for measurement of $\Delta V$ were intercompared and agreed to within 0.05 pereent throughout their range. The values of $f$ for the two chambers were determined independently by ionization means and found to be 0.0 percent for both the NBS and swedish chambers. The collecting potential for each chamber was sufficient for saturation within 0.1 percent.

The ratio of the calculated dose rates for the two instruments is

$$
\begin{aligned}
\frac{(\mathrm{r} / \mathrm{sec})_{\mathrm{S}}}{(\mathrm{r} / \mathrm{sec})_{\mathrm{B}}}= & \left(\frac{A_{\mathrm{B}} L_{\mathrm{B}}}{A_{\mathrm{S}} L_{\mathrm{S}}}\right)\left(\frac{T_{\mathrm{S}}}{T_{\mathrm{B}}}\right)\left(\frac{100+K_{\mathrm{B}}}{100+K_{\mathrm{S}}}\right) \\
& \left(\frac{100+f_{\mathrm{B}}}{100+f_{\mathrm{S}}}\right)\left(\frac{C_{\mathrm{S}}(\Delta V / \Delta t)_{\mathrm{S}}}{C_{\mathrm{B}}(\Delta V / \Delta t)_{\mathrm{B}}}\right) e^{\mu\left(d_{\mathrm{s}}-d_{\mathrm{B}}\right)}
\end{aligned}
$$

where the subscript $S$ denotes factors for the Swedish chamber and subscript B factors for the NBS ehamber. Is

$$
\begin{aligned}
\frac{A_{\mathrm{B}}}{A_{\mathrm{S}}} & =1.5678, \\
\frac{L_{\mathrm{B}}}{L_{\mathrm{S}}} & =0.5040 \\
d_{\mathrm{S}}-d_{\mathrm{B}} & =0.447-0.308=0.139 \mathrm{~m}, \\
\frac{C_{\mathrm{s}}}{C_{\mathrm{B}}} & =0.20894, \\
\frac{100+f_{\mathrm{B}}}{100+f_{\mathrm{S}}} & =1.000
\end{aligned}
$$

this ratio becomes

$$
\begin{aligned}
\frac{(\mathrm{r} / \mathrm{sec})_{\mathrm{S}}}{(1 / \mathrm{sec})_{\mathrm{B}}}=0.16509\left[\left(\frac{T_{\mathrm{S}}}{T_{\mathrm{B}}}\right)\right. & \left(\frac{100+K_{\mathrm{B}}}{100+K_{\mathrm{S}}}\right) \\
& \left.\left(\frac{(\Delta V / \Delta t)_{\mathrm{S}}}{(\Delta V / \Delta t)_{\mathrm{B}}}\right) e^{0.139_{\mu}}\right] .
\end{aligned}
$$

It is instructive to consider the detailed analysis for the $K$ of one of the chambers. Such an analysis is facilitated by plotting a vertical section of the collecting region on polar graph paper. 'The outline of the collection region for the Swedish chamber is shown by the full lines of figure 22 . The dash hines show the boundary circles for the computation. It is seen that all of the ionization within a $6.3-\mathrm{cm}$ radius is collected, but also that there is a fraction (fraction of $360^{\circ}$ ), $F$, of the ionization collected for larger diameter rings. ${ }^{\text {is }}$

\footnotetext{
I* The ionization lost by electrons striking the collector is very small, but can be taken into account by discounting the volume lying behind that electrode.
}

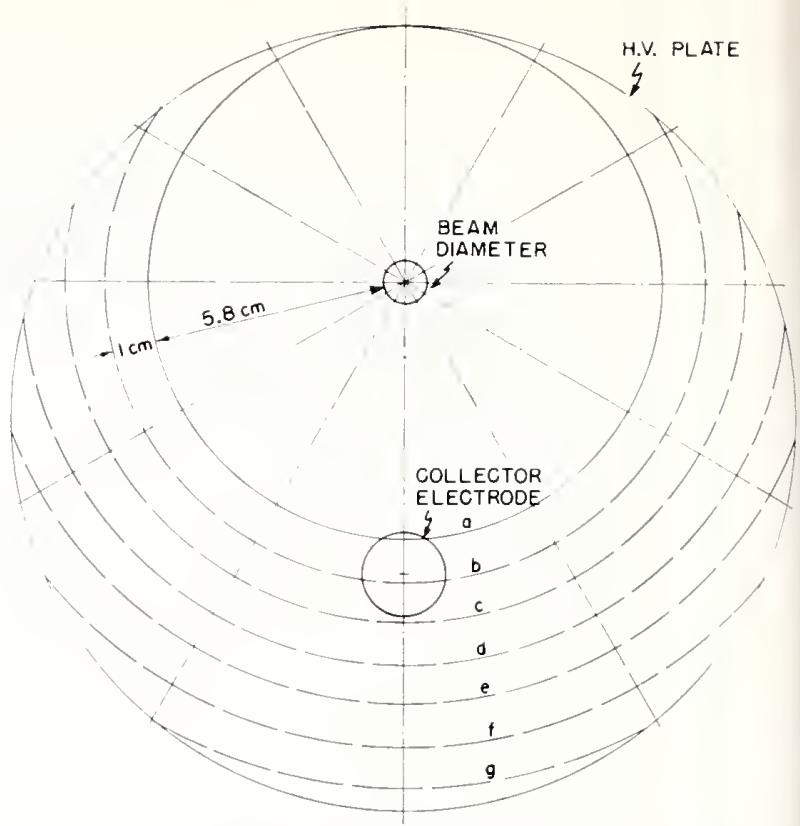

Figure 22. Section through collection region of the Swedish chamber.

The loss of electron-produced ionization, $E_{r}$, for $5.8 \mathrm{~cm}$ is obtained ${ }^{19}$ from figure 8 , and the gain of secondary photon ionization from table 2 . Table 3 shows the numbers obtained for $250-\mathrm{kv}$ X-rays. It is seen that there is an over-all loss of electron ionization of 1.19 percent and a gain of secondary photon ionization of 0.20 percent. Thus the chamber gives about 0.99 percent too low an ionization collection at $250 \mathrm{kv}$. Table 4 summarizes the computation of $K$ for the two cham-

\begin{tabular}{|c|c|c|c|c|c|c|c|c|c|}
\hline \multicolumn{2}{|c|}{ Radii } & \multirow{2}{*}{$F$} & \multirow{2}{*}{$E_{r}$} & \multirow{2}{*}{$F E_{r}$} & \multicolumn{2}{|c|}{ Radii } & \multirow{2}{*}{$F$} & \multirow{2}{*}{$S_{r}$} & \multirow{2}{*}{$F S_{r}$} \\
\hline Inner & Outer & & & & Inner & Outer & & & \\
\hline \multirow{3}{*}{$\begin{array}{r}c m \\
0 \\
5.8 \\
6.8 \\
7.8 \\
8.8 \\
9.8 \\
10.8 \\
11.8\end{array}$} & \multirow{3}{*}{$\begin{array}{r}c m \\
5.8 \\
6.8 \\
7.8 \\
8.8 \\
9.8 \\
10.8 \\
11.8 \\
12.3\end{array}$} & \multirow{3}{*}{$\begin{array}{l}1 \\
0.8 \\
.6 \\
.5 \\
.4 \\
.3 \\
.2 \\
.1\end{array}$} & \multirow{3}{*}{$\begin{array}{r}-2.15 \\
0.55 \\
.37 \\
.28 \\
.20 \\
.18 \\
.12 \\
.10\end{array}$} & \multirow{2}{*}{$\begin{array}{r}-2.15 \\
+0.44 \\
+.22 \\
+.14 \\
+.08 \\
+.05 \\
+.02 \\
+.01\end{array}$} & \multirow[t]{3}{*}{$\begin{array}{r}c m \\
0 \\
5 \\
10\end{array}$} & \multirow[t]{3}{*}{$\begin{array}{l}c m \\
5 \\
10 \\
12.3\end{array}$} & \multirow[t]{3}{*}{$\begin{array}{l}1 \\
0.7 \\
.2\end{array}$} & \multirow[t]{3}{*}{$\begin{array}{r}0.09 \\
.12 \\
.15\end{array}$} & $\begin{array}{r}+0.09 \\
+.08 \\
+.03\end{array}$ \\
\hline & & & & & & & & & \multirow[t]{2}{*}{+0.20} \\
\hline & & & & -1.19 & & & & & \\
\hline \multicolumn{10}{|c|}{$\begin{array}{l}K=F E_{r}+F S_{r} \\
K=-1.19+0.20 \\
K=-0.99\end{array}$} \\
\hline
\end{tabular}
bers at the different $\mathrm{X}$-ray potentials and filtrations. It is seen that the values vary slowly with potential so an interpolation is feasible. Table 5 shows the values of $(r / \mathrm{sec})_{\mathrm{S}} /(\mathrm{r} / \mathrm{sec})_{\mathrm{B}}$ obtained from the experimental data with corrections applied as indicated.

TABLE 3. Analysis of ionization excess in Swedish chamber for $250-k v \mathrm{X}$-rays

${ }^{19}$ The beam radius of $0.5 \mathrm{~cm}$ must be subtracted from the radii of figure 22 when determining values of $E_{r}$ and $S_{r}$. 
TABLE 4. Talues of $K$

\begin{tabular}{|c|c|c|c|c|c|c|}
\hline Chamber & $60 \mathrm{kv}$ & $75 \mathrm{kV}$ & $100 \mathrm{kv}$ & $150 \mathrm{kv}$ & $200 \mathrm{kV}$ & $250 \mathrm{kV}$ \\
\hline $\begin{array}{l}\text { Swedish } \\
\text { NBS }\end{array}$ & $\begin{array}{r}+0.32 \\
+.44\end{array}$ & $\begin{array}{r}+0.32 \\
+.44\end{array}$ & $\begin{array}{r}+0.20 \\
+.42\end{array}$ & $\begin{array}{r}-0.30 \\
+.23\end{array}$ & $\begin{array}{r}-0.74 \\
-.04\end{array}$ & $\begin{array}{r}-0.99 \\
-.20\end{array}$ \\
\hline
\end{tabular}

TABLE 5. Comparison of free-air chambers, $(\mathrm{r} / \mathrm{sec})_{\mathrm{S}} /(r / \mathrm{sec})_{\mathrm{B}}$

\begin{tabular}{|l|c|c|c|c|c|}
\hline $60 \mathrm{kv}$ & $75 \mathrm{kV}$ & $100 \mathrm{kv}$ & $150 \mathrm{kv}$ & $200 \mathrm{kv}$ & $250 \mathrm{kV}$ \\
\hline 0.995 & 0.992 & 0.995 & 0.994 & 0.996 & 0.997 \\
\hline
\end{tabular}

\section{Accuracy of Free-Air Chamber Measurements}

One can estimate the accuracy with which a measurement with a free-air chamber can be made by estimating the accuracy of each of the factors involved. Table 6 shows the estimates given by the International Commission on Radiological Units and Measurements [8]. If all of these factors act in the same direction, it is possible for an error of as much as \pm 1.1 percent to exist in a measurement. This is an unlikely occurrence, however, and the probable limit of the error is about \pm 0.5 percent.

The ICRU has also estimated that two free-air chambers when checked against each other shoukl certainly agree to within 0.9 percent, and that when two chambers are compared through an intermediary free-air chamber, one should expect an agreement to within 1.2 percent maximum. The Swedish-NBS calibration just described falls well within the 0.9 percent. 'The Swedish chamber has also been calibrated at Frankfort [30] and the proper corrections applied [17]. While the NBS Frankfort calibrations were not performed at exactly the same radiation quality, there seems to be an agreement of within 0.5 percent. Thus, the absolute determination of the roentgen can probably be made to an accuracy somewhat better than that given in table 6 .

TABLE 6. Experimental maximum error for quality range of 50 to $500 \mathrm{kv}$ (constant potential), and filtrations of $2 \mathrm{~mm}$ Al and $3 \mathrm{~mm}$. Cu respectively

\begin{tabular}{|c|c|}
\hline Experimental factor & $\begin{array}{l}\text { Estimated max- } \\
\text { imum error }\end{array}$ \\
\hline $\begin{array}{l}\text { Charge (assumed measured by aceurate potenti- } \\
\text { ometer and capacitor using electrometer as a } \\
\text { null detector) }\end{array}$ & $\begin{array}{l}\text { Percent } \\
\pm 0.1\end{array}$ \\
\hline $\begin{array}{l}\text { Air volume (ineludes errors in diaphragm area, } \\
\text { collecting plate alinement, and field distortion } \\
\text { resulting from other causes) }\end{array}$ & \pm 3 \\
\hline $\begin{array}{l}\text { Air density (includes pressure and temperature } \\
\text { measurements) }\end{array}$ & \pm .1 \\
\hline $\begin{array}{l}\text { Humidity of the air (ineludes measurement of the } \\
\text { lumidity and the effeet of a slightly different } \\
\text { value of the average cnergy per ion pair (III) for } \\
\text { water vapor) }\end{array}$ & 土. 1 \\
\hline Saturation of ion collection & \pm .1 \\
\hline Scattering of $\mathrm{X}$-rays by air in the chamber & t. 1 \\
\hline $\begin{array}{l}\text { Inadequaey of plate separation for electron path } \\
\text { length }\end{array}$ & \pm .1 \\
\hline Air attenuation between diaphragm and colleetor.. & 土. 2 \\
\hline
\end{tabular}

\section{References}

[1] L. A. W. Kemp and S. M. Hall, A precision investigation of some aspects of parallel-plate free-air chamber geometry, Brit. J. Radiol. 27, 219 (1954).

[2] H. O. Wyckoff, G. H.' Aston, and E. E. Smith, A comparison of X-ray standards, Brit. J. Radiol. 27, 325 (1954); Acta Radiol. Suppl. 117, 17 (1954).

[3] F. H. Attix and L. DeLaVergne, Plate separation requirements for free-air ionization chambers, Radiology 63, 853 (1954); J. Research NBS 53, 393 (1954), RP2558.

[4] W. Miller and R. J. Kennedy, Measurement of field distortion in free-air ionization chambers by an analog method, J. Research NBS 55, 291 (1955), RP2632.

[5] H. O. Wyckoff and F. S. Kirn, Standard chamber requirements for 250 - to 500 -kilovolt $\mathrm{X}$-rays, J. Research NBS 58, 111 (1957), R P2741.

[6] G. H. Aston and F. H. Attix, An intercomparison of the roentgen standards of Great Britain and U. S. A., Acta Radiologica 46, 747 (1956).

[7] R. Thoraeus and H. O. Wyckoff, Calibration of the portable Swedish free-air chamber equipment at the U. S. National Bureau of Standards, Acta Radiologica 46, 741 (1956).
[8] NBS Handbook 62, Report of the International Commission on Radiological Units and Measurements (Superintendent of Documents, Government Printing Office, Washington, D. C., 1956).

[9] U. Fano, Note on the Bragg-Gray cavity principle for measuring energy absorption, Radiation Research 1, 237 (1954).

[10] R. Thoraeus, The status of roentgen-ray standards in Sweden and a brief report of the first part of an intercomparison between national roentgen-ray standards, Acta Radiologica Suppl. 117, 33 (1954).

[11] H. Kustner, Über dic Luftionisation durch Röntgenstrahlen verchiedener Härte und verschiedenen Homogenitätsgrades, Ann. d. Phys. 10, 616 (1931); W. I. Block, Die Luftionisation durch Röntgenstrahlen verschiedenen Härte und verschiedenen Homogenitätsgrades bis zu $400 \mathrm{kv}$, Ann. d. Phys. 32, 701 (1938).

[12] IIandbook of Chemistry and Physics, 36th ed., p. 1965 (Chemical Rubber Publishing Co., Cleveland, Ohio, 1954).

[13] L. S. Taylor, Analysis of diaphragm system for the X-ray standard ionization chamber, Radiology 15, $49(1930)$. 
[11] G. Failla, Department of Radiology, Columbia University, New York, N. Y., private communication.

[15] C. König, Der Einfluss den Blende auf die Absoluthestimmung der r-Einheit, Phys. Zeit. 40, 46 (1939).

[16] L. S. Taylor, International comparison of X-ray standirdk, J. Research NBS 8, 9 (1932), RP397.

[17] G. H. Aston, National Physical Laboratory, Teddington, Middlesex, England, private communication.

[18] E. Bunde, A. Sewkor, B. Rajewsky, and R. Jaeger, Verifizierung des " $r$ " bei Röntgenstrahlen im Bereich $5 \mathrm{kV}$ bis $50 \mathrm{kV}$ Erzeugungsspannung, Acta Radiologica 44, 163 (1955).

[19] L. S. Taylor and G. Singer, An improved form of standard ionization chamber, Radiology 15, 637 (1930).

[20] G. Failla and L. D. Marinelli, The measurement of the ionization produced in air by gamma rays, Am. J. Roentgenol. Radium Therapy 38, 312 (1937).

[21] C. Garrett, National Research Council, Ottawa, Ontario, Canada, private communication.

[22] L. A. W. Kemp, London Hospital, Whitechapel, London, England, private communication.

[23] W. Duane and E. Lorenz, Standard ionization chamber for roentgen-ray dosage measurement, Am. J. Roentgenol. 19, 461 (1928).

[24] G. 1. Roth, New Zealand Dept. of Health, Christchurch, New Zealand, private communication.
[25] L. S. Taylor, The precise measurement of X-ray dosage, Radiology 14, 372 (1930).

[26] E. Kara-Michailova and D. E. Lea, The interpretation of ionization measurement in gases at high pressures, Proc. Phil. Soc. 36, 101 (1940).

[27] W. Niller and R. J. Kennedy, X-ray attenuation in lead, aluminum, and concrete in the range 275 to 525 kilovolts, Radiology 65, 920 (1955).

[28] A. H. Scott, Measurement of multimegohm resisiors, J. Research NBS 50, 147 (1953) RP2402.

[29] D. J. De Bitetta, Electrometer fluctuation compensating device, Rev. Sci. Instr. 26, 986 (1955).

[30] R. Thoraeus, et al, Vergleichsmessungen des internationalen "röntgen" im Bereich von $8 \mathrm{kV}$ bis 170 $\mathrm{kV}$ Erzeugungsspannung, Strahlentherapie 98, 265 (1955).

[31] O. Glasser, E. II. Quimby, L. S. Taylor, and J. L. Weatherwax, Physical Foundations of Radiology, 2d ed. (Paul B. Höeber, Ine., New York, N. Y., 1952).

[32] B. Rajewsky, E. Bunde, M. Dorneich, D. Lang, A. Sewkor, R. Jaeger, and W. Hubner, Darstellung, Wahrung und Úbertragung der Einheit der Dosis für Röntgen- und Gammastrahlen mit Quantenenergien zwischen $3 \mathrm{keV}$ und $500 \mathrm{keV}$ (PhysikalischTechnische Bundesanstalt, Braunschweig, Germany, 1955).

Washington, May 14, 1957. 


\section{THE NATIONAL BUREAU OF STANDARDS}

The scope of activities of the National Bureau of Standards at its headquarters in Washington, D. C., and its major field laboratories in Boulder, Colorado, is suggested in the following listing of the divisions and sections engaged in technical work. In general, each section carries out specialized research, development, and engineering in the field indicated by its title. A brief description of the activities, and of the resultant publications, appears on the inside front cover.

\section{WASHINGTON, D. C.}

Electricity and Electronics. Resistance and Reactance. Electron Devices. Electrical Instruments. Magnetic Measurements. Dielectrics. Engineering Electronics. Electronic Instrumentation. Electrochemistry.

Optics and Metrology. Photometry and Colorimetry. Optical Instruments. Photographic Technology. Length. Engineering Metrology.

Heat. Temperature Physics. Thermodynamics. Cryogenic Physics. Rheology. Engine Fuels. Free Radicals Research.

Atomic and Radiation Physics. Spectroscopy. Radiometry. Mass Spectrometry. Solid State Physics. Electron Physics. Atomic Physics. Neutron Physics. Nuclear Physics. Radioactivity. X-rays. Betatron. Nucleonic Instrumentation. Radiological Equipment. AEC Radiation Instruments.

Chemistry. Organic Coatings. Surface Chemistry. Organic Chemistry. Analytical Chemistry. Inorganic Chemistry. Electrodeposition. Molecular Structure and Properties of Gases. Physical Chemistry. Thermochemistry. Spectrochemistry. Pure Substances.

Mechanics. Sound. Mechanical Instruments. Fluid Mechanics. Engineering Mechanics. Mass and Scale. Capacity, Density, and Fluid Meters. Combustion Controls.

Organic and Fibrous Materials. Rubber. Textiles. Paper. Leather. Testing and Specifications. Polymer Structure. Plastics. Dental Research.

Metallurgy. Thermal Metallurgy. Chemical Metallurgy. Mechanical Metallurgy. Corrosion. Metal Physics.

Mineral Products. Engineering Ceramics. Glass. Refractories. Enameled Metals. Concreting Materials. Constitution and Microstructure.

Building Technology. Structural Engineering. Fire Protection. Air Conditioning, Heating, and Refrigeration. Floor, Roof, and Wall Coverings. Codes and Specifications. Heat Transfer. Applied Mathematics. Numerical Analysis. Computation. Statistical Engineering. Mathematical Physics.

Data Processing Systems. SEAC Engineering Group. Components and Techniques. Digital Circuitry. Digital Systems. Analog Systems. Application Engineering.

- Office of Basic Instrumentation

- Office of Weights and Measures

\section{BOULDER, COLORADO}

Cryogenic Engineering. Cryogenic Equipment. Cryogenic Processes. Properties of Materials. Gas Liquefaction.

Radio Propagation Physics. Upper Atmosphere Research. Ionospheric Research. Regular Propagation Services. Sun-Earth Relationships.

Radio Propagation Engineering. Data Reduction Instrumentation. Modulation Systems. Navigation Systems. Radio Noise. Tropospheric Measurements. Tropospheric Analysis. Radio Systems Application Engineering.

Radio Standards. High Frequency Electrical Standards. Radio Broadcast Service. High Frequency Impedance Standards. Calibration Center. Microwave Physics. Microwave Circuit Standards. 


\section{HANDBOOKS OF THE NATIONAL BUREAU OF STANDARDS}

The following Handbooks issued by the Bureau are available by purchase from the Superintendent of Documents, Government Printing Office, Washington 25, D. C., at the prices indicated:

Screw-Thread Standards for Federal Services 1957, Part I (Amends in part H28 1944 and in part it's 1950 Supplement)

Installation and Maintenance of Electric Supply and Communication Lines, Safety Rules and Discussion.

Specifications, Tolerances, and Regulations for Commercial Weighing and Measuring Devices-2d Edition. - .

Code for Protection Against Lightning --

48 Control and Removal of Radioactive Contamination in Laboratories. .........

Recommendations for Waste Disposal of Phosphorus-32 and Iodine-131 for Medical Users - - -

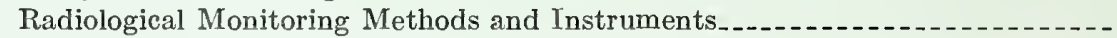

Maximum Permissible Amounts of Radioisotopes in the Human Body and Maximum Permissible Concentrations in Air and Water tron Volts

Safe Handling of Cadavers Containing Radioactive Isotopes................

Photographic Dosimetry of X- and Gamma Rays...............................

Radioactive-Waste Disposal in the Ocean . . . . .

Permissible Dose From External Sources of Ionizing Radiation. .

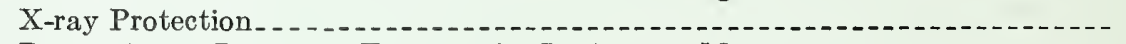

Regulation of Radiation Exposure by Legislative Means

Report of the International Commission on Radiological Units and Measurements (ICRU) 1956 